This paper is a postprint of a paper submitted to and accepted for publication in IEEE Journal of Emerging and Selected Topics in Power Electronics and is subject to Institution of Electrical and Electronic Engineering Copyright. The copy of record is available at IEEE Xplore Digital Library

\title{
Half and Full-Bridge Modular Multilevel Converter Models for Simulations of Full-Scale HVDC Links and Multi-terminal DC grids
}

\author{
G.P. Adam, IEEE Member, and B.W. Williams
}

\begin{abstract}
This
Abstract-This paper presents an improved
electromagnetic transient (EMT) simulation models for the

Abstract-This paper presents an improved
electromagnetic transient (EMT) simulation models for the

Abstract-This paper presents an improved
electromagnetic transient (EMT) simulation models for the half and full-bridge modular multilevel converters that can be used for full-scale simulation of multilevel high-voltage dc transmission systems, with hundreds of cells per arm. The presented models employ minimum software overhead within their electromagnetic transient parts to correctly represent modular multilevel converters (MMC) behaviour during de network faults when converter switching devices are blocked. The validity and scalabilities of the presented models are demonstrated using open loop simulations of the half and full-bridge MMCs, and closed loop simulation of a full-scale HVDC link, with 201 cells per arm that equipped with basic HVDC controllers, including that for suppression of the $2^{\text {nd }}$ harmonic currents in the converter arms. The results obtained from both demonstrations have shown that the presented models are able to accurately simulate the typical behaviour of the MMC during normal, and ac and dc network faults.
\end{abstract}

Key words-electromagnetic transient simulation; highvoltage dc transmission system; half and full-bridge modular multilevel converter; and hybrid multilevel converters.

\section{INTRODUCTION}

Increased operational flexibilities of the voltage source converter based high-voltage dc (VSC-HVDC) transmission system within ac power systems in the last decade have encouraged its universal acceptance by the power system utilities worldwide[1-12]. Additionally, its evolution from that build around the two-level and neutral-point clamped converter topologies to that built using true multilevel converters, with low semiconductor losses and improved ac side waveforms quality have accelerated its adoption in many of the recent HVDC transmission systems projects[13-19]. Replacing of the traditional concept of voltage source converter that uses concentrated reservoir capacitors at the converter dc input by that uses distributed capacitors such as that in modular multilevel converter has improved the resiliency of the VSC-HVDC transmission systems to ac and dc network faults[20-27]. For aforementioned reasons, modular multilevel converter has become the preferred technology for large-scale HVDC links and de grids that could ensure safe and reliable operation during ac and dc network disturbances.

Full-scale modelling of the VSC-HVDC links that use half or full bridge cell modular converters, with hundreds of cells per arm is computationally intensive task that requires machines with high computing power and large memory, and takes long time to simulate. The traditional switching models that use power electronic building blocks with full capabilities of mimicking conduction of the physical devices (such as IGBT

G.P. Adam and B.W. Williams are with the Electronic and Electrical Engineering Department, University of Strathclyde, Glasgow, UK (email: grain.adam@strath.ac.uk and barry.williams@strath.ac.uk). and its anti-parallel) are proven to be inefficient for full-scale modelling of the MMC based HVDC links as simulation times become prohibitively long. Despite the above shortcomings, this approach remains widely used, where transient response of the MMC based HVDC links to ac and de network faults are studied using reduced number of cells. This is because the switching model is extremely useful when comes to capturing of the MMC internal dynamics in great details during ac and dc network faults. In attempt to reduce simulation time, the authors in $[28,29]$ presented an averaged model of the MMC based HVDC link where the ac component of the MMC upper and lower arms modulation functions are obtained directly from the inner current controller and appropriate dc offsets are added. These modulating functions are used as inputs to the two controlled voltage sources that mimicked the voltage developed across MMC upper and lower arms. The main weakness of this approach is that it does not allow natural development of the arm current dc component and circulating current, thus not able to naturally developed dc power as in real world MMC. For this reason, the authors in [28, 29]included additional stage that artificially injects dc components into converter arms, estimated based on power balance principle, and also this stage has been used to mimic MMC converter operation during gate blocking as required during dc network fault. Additionally, injection of the dc components into converter arm currents as in $[28,29]$ results in instantaneous balance between MMC ac and dc powers, and this deprives the approach presented in [28, 29] from accurately reproduce the dc power dynamics due to MMC inertia and propagation delays due to arm and dc line inductances (inductances in the dc current paths). Although, the approach in [28, 29] provides an efficient way of modelling MMC based HVDC link for general system level studies, it cannot reproduce MMC internal dynamics at microscopic levels as required in design stage and for protection purposes during ac and dc network faults.

Reference [30] presented an efficient method for full-scale modelling of the MMC based HVDC link that uses electromagnetic transient approach. The authors in [30] use Dommel's Norton and Thevenin equivalent circuits of the MMC cell capacitors, and two-state resistor representation of the switching devices to reduce the entire arm of the MMC to a simple Thevenin equivalent circuit, with two terminals. This approach significantly reduces computation burden that arises from solution of the power circuit, while that due to modulation and capacitor voltage balancing is retained as in detail switching models. Despite above simplification, this approach is able to capture some of the MMC internal dynamics that associated with the cell capacitor voltages and arm currents, and also allow natural development of the dc and circulating current components of the MMC arms, hence, it is able to reproduce the dynamics of the dc power. However, the electromagnetic transient approach as discussed in reference [30] cannot reproduce dynamic interaction between ac and dc sides during de network fault.

The accelerated model of the MMC presented in [31] is developed in similar theoretical basis as that in [30], except 
This paper is a postprint of a paper submitted to and accepted for publication in IEEE Journal of Emerging and Selected Topics in Power Electronics and is subject to Institution of Electrical and Electronic Engineering Copyright. The copy of record is available at IEEE Xplore Digital Library

the authors unknowingly have treated each individual MMC from both demonstrations have shown that the presented cell as a primitive circuit that share the same current injection MMC model is able to reproduce the typical behaviour of equal to the arm current, and this assumption permits MMC based HVDC links to microscopic level in all the above application of the generalized circuit theory by Kron [32-34] . studies. This qualifies the presented MMC model to be used Additionally, this allows Kron connection matrix to be for detailed studies of the MMC based HVDC links at design constructed using relationships between arm current and stage such as fine tuning of MMC passive parameters, and individual cell currents, and such connection matrix can be validation of the control and protection systems.

used to prove that validity of the approach presented in [31].

The accelerated MMC model in its present form has the same attributes and limitations of that presented in [30]. Nevertheless, they remain the only practical ways to simulate full-scale MMC based HVDC link, with hundreds of cells per arm.

The authors in [35] presented two simplified MMC fundamental average models for slow dynamic studies that deliberately ignore converter switching actions and dynamics of the cell capacitors, while considering that of the ac side in order to enable the use of large time step and reduce simulation time. Reference [35] has shown that this approach is suitable for transient and small signal stability studies where manipulation of the converter output active and reactive powers are useful for improving stability of the ac parts of the power systems; but it is inappropriate for use in any studies that concern with the dc side and fast transient. Furthermore, both MMC models proposed in [35] are unable to naturally developed dc current components of the arm currents; thus, unable to produce dc power naturally.

The authors in $[36,37]$ proposed an interesting approach that uses a factitious network known as Surrogate to model fullscale MMC based HVDC link. This approach replaces the actual MMC cells in each converter arm by their Surrogate equivalents that produce the same computational results as the true cells. Surrogate network for each arm of the half or fullbridge MMC contains three sub-networks that represent converter blocking state, sub-modules bypass state, and positive and negative sub-modules insertion states. This approach is appeared to be promising for large-scale modelling of the multi-terminal HVDC networks where MMC internal dynamics are less important. References [36, 37] have demonstrated the suitability of Surrogate network modelling approach of the MMC for real-time simulation and hardware in loop, with much smaller time step than other commercially available real-time digital simulators. However, its ability to accurately simulate dc fault is yet to be seen.

This paper improves the MMC modelling approach presented in [31] to be able to simulate the performance of full-scale MMC based HVDC links during ac and dc network faults, and to capture its internal dynamics to microscopic levels (cell capacitor voltages, arm currents, current stresses in switching devices, and dynamics of ac and dc powers). The ability to simulate dc fault is achieved by setting values of the two-state resistors that represent the MMC switching devices to mimic exactly the physical operation of gate insulated bi-polar transistors(IGBT) and their anti-parallel diodes during gate blocking, taking into account arm currents polarities. The first part of this paper presents an open loop demonstrations of the half and full-bridge MMC, including validation of the presented half-bridge MMC model against its switching counterpart, and scalability of the full-bridge MMC model. The second part of this paper presents a closed loop demonstration that uses a full-scale model of the half-bridge MMC based HVDC to simulate its performance during normal operation, and ac and dc network faults. The results obtained

\section{REVIEW OF THE MODULAR MULTILEVEL CONVERTER}

Figure 1 shows three-phase generic modular multilevel converter with $\mathrm{N}$ cells per arm. For input dc link voltage ' $V_{d c}$ ', voltage stress across each switching devices is $V_{d c} / \mathrm{N}$, provided that the voltage across each cell capacitor is maintained at $V_{d c} / N$ [38-41]. In each instant, $K$ and $N-K$ cell capacitors from the upper and lower arms must be inserted in the power path in order synthesize different output voltage levels. This ensures that $v_{a 1}+v_{a 2}=V_{d c} \pm \Delta v$; where $v_{a 1}$ and $v_{a 2}$ represent voltages across the upper and lower arms of phase ' $\mathrm{a}$ ', and $\Delta \mathrm{V}$ represents ac plus dc voltage drop in the internal resistance $\left(R_{d}\right)$ and inductance $\left(L_{d}\right)$ of the arm reactors. In other words, from $2 N$ available cell capacitors in each phase (upper and lower arms) of the modular converter, only $N$ cell capacitors must be switched into the power path while the $N$ remaining cell capacitors must be bypassed. Such restriction necessitates complementary operation of the upper and lower arms of the modular converter[42]. Since modular converter synthesizes the amplified version of the modulating signals (sinusoidal output voltage) by insertion of its cell capacitors into power path sequentially, flow of fundamental current through these capacitors plus voltage drop across arm reactors will cause the cell capacitor voltages to oscillate around fixed dc component. The exact value of the cell capacitor voltages dc component is influenced by power flow direction, and can be determined by $\left(V_{d c} \pm 2 R_{d} I_{d}\right) / N$; where $I_{d}$ is the arm current dc component. Oscillation of the upper cell capacitor voltages against that of the lower arm, and that of individual phase against main dc link voltage cause additional current components to flow in the modular converter arms (inrush plus circulating currents). The inrush currents are cause by switching of the cell capacitor in and out of the power path for the purpose of maintaining capacitor voltage balancing, and oscillation of the upper arm against the lower arm. The circulating currents are caused by oscillation of individual phase arm voltages such as $v_{a 1}+v_{a 2}, v_{b 1}+v_{b 2}$ and $v_{c 1}+v_{c 2}$ against the main dc link voltage $\left(\mathrm{V}_{\mathrm{dc}}\right)$; where $v_{b 1}$ and $v_{b 2}$, and $v_{c 1}$ and $v_{c 2}$ are the voltage developed across the upper and lower arm cell capacitors of the phases $b$ and $c$.

Unlike conventional voltage source converters, the upper and lower arms of the modular converter conduct simultaneously, and this result in each arm contributes half of the output phase current, thus, half of the ac power per phase converter exchanges with the ac side. The power exchange between each phase and dc side is achieved through dc power, which is related to $I_{d}(d c$ component of the arm current). Flow of the three current components in the semiconductor switches cause modular converter to have higher on-state loss when compared to traditional voltage source converters such as two-level and neutral-point clamped[43]. Since fundamental and dc components of the arm currents are necessary for power exchange between ac and dc sides, the inrush and circulating current component of the arm current must be minimized in 
This paper is a postprint of a paper submitted to and accepted for publication in IEEE Journal of Emerging and Selected Topics in Power Electronics and is subject to Institution of Electrical and Electronic Engineering Copyright. The copy of record is available at IEEE Xplore Digital Library

order to reduce modular multilevel converter on-state loss as signal blocking as happens during de short circuit faults, $R_{x i}$ discussed in [44-46]. However, active suppression of the $2^{\text {nd }}$ and $R_{a i}$ are set based on the arm current polarity and peak of harmonic in the arm current, which is the dominant component line-to-line voltages. Line-to-line voltages at converter of the circulating current as suggested in [47-52] is associated terminals are used to mimic diode rectifier operation of the with additional switching losses, and also limits the maximum typical MMC when gate signals are inhibited. Arm currents attainable modulation index (hence, results in smaller polarities are used to mimic conduction of the anti-parallel converter P-Q envelope). Method that uses passive filter to diodes of the switching devices $S_{x i}$ and $S_{a i}$. For example, suppress arm current circulating in the modular converter is assume arm current $I_{m i}$ in Figure 2 (a) and (b) is positive, when proposed in [53]. This method avoids the shortcoming of the $I_{m i}<0, R_{a i}$ for all cells in the upper and lower arms that expose previous method that actively suppresses arm circulating maximum line-to-line voltage are set on, and all remaining current, but its downside is that it requires additional passive switches must set to off-state (typical diode rectifier component, which may slightly increase converter station operation). When $I_{m i}>0$, and $R_{x i}$ for the entire arm must be on footprint and losses. For more details on the modulation and to mimic the gate blocking condition in typical MMC cell capacitor voltage balancing adopted in this paper, refer to operation when the conduction path is through anti-paralle $[41,42,44,54-60]$.

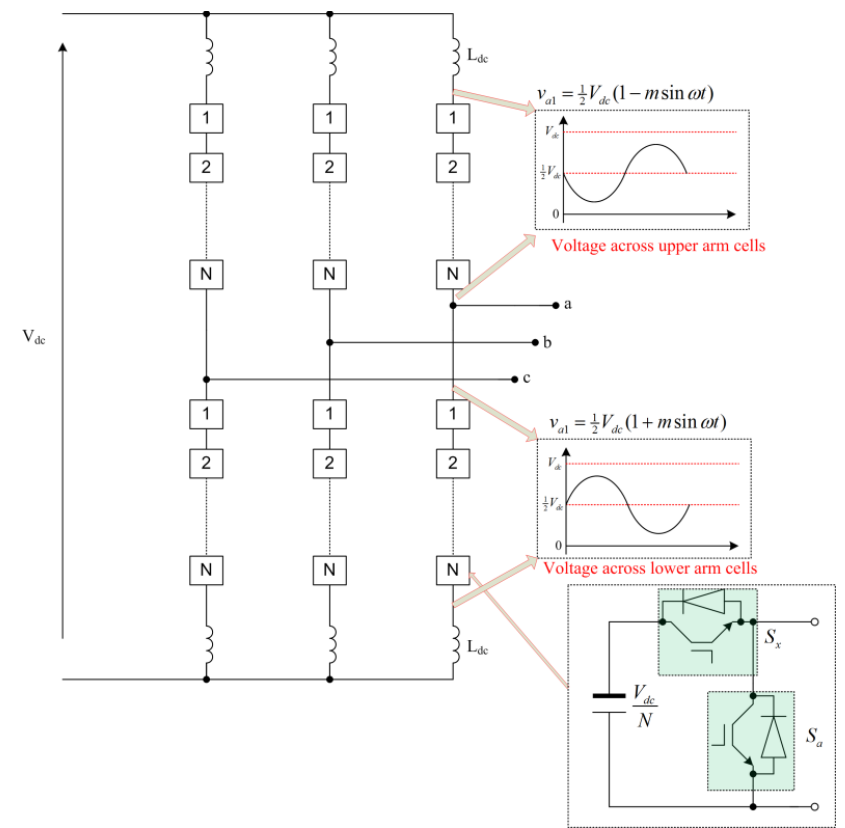

Figure 1: Schematic diagram of generic three-phase modular multilevel converter

\section{GENERIC ELECTROMAGNETIC TRANSIENT MODELLING OF MODULAR MULTILEVEL CONVERTER}

\section{A) Half-bridge MMC model}

Figure 2 (a) and (b) show half-bridge cell version of the modular multilevel converter and its electromagnetic transient representation based on Dommel trapezoidal method. Switching devices $S_{x i}$ and $S_{a i}$ in Figure 2(a) are replaced by switched resistances $R_{x i}$ and $R_{a i}$ in the electromagnetic transient simulation equivalent circuit in Figure 2(b). The cell capacitor in Figure 2(a) is replaced by its trapezoidal Norton equivalent circuit in Figure 2(b). When switching devices $S_{x i}$ or $S_{a i}$ are on their corresponding switched resistances are set to $R_{o n 1}$ or $R_{o n 2}$ (on-state resistances of the switches $S_{x i}$ and $S_{a i}$ ). When $S_{x i}$ or $S_{a i}$ are off their corresponding switched resistances are set to $R_{\text {off } 1}$ or $R_{\text {off } 2}$ (off-state resistances of the switches $S_{x i}$ and $S_{a i}$ ). Switched resistances $R_{x i}$ and $R_{a i}$ are set to mimic operation of typical switches of the modular converter when they receive gating signals from the modulator. Thus, during normal operation, $R_{x i}$ and $R_{a i}$ are set on and off in complementary manner as in typical operation of $S_{x i}$ and $S_{a i}$ in MMC [41, 42, 61]. To mimic MMC operation during gate diodes of $S_{x i}$ and cell capacitors. In this manner, the electromagnetic transient representation of the MMC cell mimics the exact operation of the physical half-bridge MMC cell operation in all operating modes.

For full MMC representation, this paper adopted per arm representation of the $\mathrm{MMC}$ in [31] that considers each arm of MMC comprises of $\mathrm{N}$ individual cells driven by one current source its value equal to arm current, and each cell generates voltage $v_{m i}$ between its terminals ( $x_{i}$ relative to imaginary ground). The total voltage developed across each converter arm is assumed to be equal to sum of the cell voltages ( $V_{a r m}=\sum_{i=1}^{N} V_{m i}$ ), where $\mathrm{N}$ is the number of cells per arm. Assuming the imaginary ground of each cell is located at its zero voltage level, the nodal equation that describes dynamics of each cell within each time step $\Delta t$ can be expressed as follow:

$$
\left[\begin{array}{cc}
\frac{1}{R_{x i}}+\frac{1}{R_{a i}} & -\frac{1}{R_{x i}} \\
-\frac{1}{R_{x i}} & \frac{1}{R_{x i}}+\frac{2 C}{\Delta t}
\end{array}\right]\left[\begin{array}{l}
V_{x i} \\
V_{y i}
\end{array}\right]=\left[\begin{array}{c}
I_{m i} \\
I_{h c i}
\end{array}\right]
$$

Where $V_{x i}$ and $V_{y i}$ represent the nodal voltages of the node $y$ and $x$ in the $i^{\text {th }}$ cell measured relative to virtual ground of the same cell. Observe that $V_{x i}$ and $V_{y i}$ represent the $i^{\text {th }}$ cell output and capacitor voltages respectively. Therefore, $V_{m i}=V_{x i}$ and $V_{c i}=V_{y i}$. The current of each cell is defined based on Dommel trapezoidal integration method as:

$$
I_{h c i}=I_{c i}(t-\Delta t)+\frac{2 C}{\Delta t} V_{c}(t-\Delta t)
$$

Instantaneous currents in the composite switches $S_{x i}$ and $S_{a i}$ (IGBT plus anti-parallel diode) are:

$$
\begin{aligned}
& I_{S x i}=\frac{V_{x i}-V_{y i}}{R_{x i}} \\
& I_{S x i}=\frac{V_{x i}}{R_{a i}}
\end{aligned}
$$

However, this paper does not formulate nodal equation matrix for the entire arm as in [31], instead it computes the cell output and capacitor voltages for $\mathrm{N}$ cells directly from (1) as:

$$
\begin{aligned}
& V_{m i}(t)=V_{x i}(t)=\frac{1}{\Omega}\left[\left[\frac{1}{R_{x i}}+\frac{2 C}{\Delta t}\right] I_{m i}+\frac{1}{R_{x i}} I_{h c i}\right] \\
& V_{c i}(t)=V_{y i}(t)=\frac{1}{\Omega_{i}}\left[\frac{1}{R_{x i}} I_{m i}+\left[\frac{1}{R_{x i}}+\frac{1}{R_{a i}}\right] I_{h c i}\right]
\end{aligned}
$$

Where $\Omega_{i}=\frac{1}{R_{x i}} \times\left[\frac{1}{R_{a i}}+\frac{2 C}{\Delta t}\right]+\frac{2 C}{\Delta t} \times \frac{1}{R_{a i}}$; and observe that for $N$ cells, equations (5) and (6) need to be solved $\mathrm{N}$ times single 
This paper is a postprint of a paper submitted to and accepted for publication in IEEE Journal of Emerging and Selected Topics in Power Electronics and is subject to Institution of Electrical and Electronic Engineering Copyright. The copy of record is available at IEEE Xplore Digital Library

time step, without the need for matrix inversion, and voltage capacitors of the full-bridge MMC will be charged for positive developed across converter arm is computed as explained and negative arm currents. The nodal equation that describes above. In this manner, computation intensity of the model is the dynamics of Dommel electromagnetic transient model of greatly reduced. Figure 2(e) and (f) show typical MMC arm the full-bridge MMC in Figure 2 (d) within each time step is: and its electromagnetic transient equivalent circuit, and Figure 3 shows one phase leg of the MMC, including interfacing of the electromagnetic transient part into Simulink SimPower building blocks.

\section{B) Full-bridge MMC model}

Figure 2 (c ) and (d) show typical full-bridge MMC cell and its electromagnetic transient equivalent circuit. Observe that the switching devices $S_{i 1}$ through $S_{i 4}$ are replaced by the switched resistances $R_{i 1}$ through $R_{i 4}$, and cell capacitor by its Norton equivalent. During normal operation, $\mathrm{R}_{\mathrm{i} 1}$ and $\mathrm{R}_{\mathrm{i} 3}$ are set on and off to produce cell output voltage $V_{m i}$ equal to $V_{c i}, 0$ and $-V_{c i}$ at

$$
\left[\begin{array}{ccc}
\frac{1}{R_{i 1}}+\frac{1}{R_{i 2}} & -\frac{1}{R_{i 1}} & -\frac{1}{R_{i 2}} \\
-\frac{1}{R_{i 1}} & \frac{1}{R_{i 1}}+\frac{1}{R_{i 3}}+\frac{2 C}{\Delta t} & -\frac{2 C}{\Delta t} \\
-\frac{1}{R_{i 2}} & -\frac{2 C}{\Delta t} & \frac{1}{R_{i 2}}+\frac{1}{R_{i 4}}+\frac{2 C}{\Delta t}
\end{array}\right]\left[\begin{array}{c}
V_{x i} \\
V_{y i} \\
V_{z i}
\end{array}\right]=\left[\begin{array}{c}
I_{m i} \\
I_{h c i} \\
-I_{h c i}
\end{array}\right]
$$

Where, each cell output and capacitor voltages are defined as:

$$
\begin{aligned}
& V_{m i}=V_{x i} \\
& V_{c i}=V_{y i}-V_{z i}
\end{aligned}
$$

node $x_{i}$ relative to cell virtual ground, and operation of Currents in the switching devices of each cell can be expressed switched resistances $R_{i 2}$ and $R_{i 4}$ are complementary to that of as explained in the half-bridge MMC case. The voltage $R_{i 1}$ and $R_{i 3}$ respectively. $V_{m i}=V_{c i}$ is achieved by setting $R_{i 1}=R_{o n}$ develops across each converter arm is expressed as the sum of and $R_{i 3}=R_{o f f} ; V_{m i}=-V_{c i}$ is achieved by setting $R_{i l}=R_{o f f}$ and the individual cell output voltage.

$R_{i 3}=R_{o n}$; and $V_{m i}=0$ can be achieved either by setting $R_{i l}=R_{o n}$ For large number of cell as will be considered later in this and $R_{i 3}=R_{o n}$ or vice versa. During gate blocking, arm current paper, matrix inversion must be avoided to reduce polarity is used to set the switched resistances of the computation burden on the processor (intensity) by preequivalent cell in the entire arm simultaneously. For example, calculation of the node voltages as:

assuming $I_{m i}$ in Figure $2(\mathrm{~d})$ is positive, $R_{i l}=R_{o n}$ and $R_{i 3}=R_{o f f}$ for $I_{m i}>0$, and $R_{i 1}=R_{o f f}$ and $R_{i 3}=R_{o n}$ for $I_{m i}<0$. Observe that because as the total voltage across cell capacitors is greater than the peak of line voltage, the cell capacitors will oppose the current flow in the arm, and there is no direct path for the current to flow through the switched resistances as in halfbridge cell case. Additionally, in case the total voltage across the cell capacitors of the all three phases happen to be smaller than the peak line voltage during the gate blocking, the cell

$$
\begin{aligned}
& V_{x i}=\frac{1}{\Omega_{i}}\left[\alpha_{11} I_{m i}+\left(\alpha_{12}-\alpha_{13}\right) I_{h c i}\right] \\
& V_{y i}=\frac{1}{\Omega_{i}}\left[\alpha_{21} I_{m i}+\left(\alpha_{22}-\alpha_{23}\right) I_{h c i}\right] \\
& V_{z i}=\frac{1}{\Omega_{i}}\left[\alpha_{31} I_{m i}+\left(\alpha_{32}-\alpha_{33}\right) I_{h c i}\right]
\end{aligned}
$$

Where: $\alpha_{11}=\Delta t\left(R_{i 1}+R_{i 3}\right)\left(R_{i 2}+R_{i 4}\right)+2 R_{i 2} R_{i 4}\left(R_{i 1}+R_{i 3}\right) C+2 R_{i 1} R_{i 3}\left(R_{i 2}+R_{i 4}\right) C ; \alpha_{12}=\alpha_{21}=R_{i 3}\left[\Delta t\left(R_{i 2}+R_{i 4}\right)+2 R_{i 4} C\left(R_{i 2}+R_{i 1}\right)\right]$, $\alpha_{13}=\alpha_{31}=R_{i 4}\left[\Delta t\left(R_{i 3}+R_{i 1}\right)+2 R_{i 3} C\left(R_{i 2}+R_{i 1}\right)\right] ; \alpha_{22}=R_{i 3}\left[\Delta t\left(R_{i 1}+R_{i 2}+R_{i 4}\right)+2 R_{i 4} C\left(R_{i 2}+R_{i 1}\right)\right] ; \alpha_{23}=\alpha_{32}=R_{i 3} R_{i 4}\left[\Delta t+2 C\left(R_{i 2}+R_{i 1}\right)\right] ;$ $\alpha_{33}=R_{i 4}\left[\Delta t\left(R_{i 1}+R_{i 2}+R_{i 3}\right)+2 R_{i 3} C\left(R_{i 2}+R_{i 1}\right)\right]$; and $\left.\left.\Omega_{i}=\Delta t\left[R_{i 1}+R_{i 2}+R_{i 3}+R_{i 4}\right)\right]+2 C\left[R_{i 1} R_{i 3}+R_{i 2} R_{i 3}+R_{i 1} R_{i 4}+R_{i 2} R_{i 4}\right)\right]$.

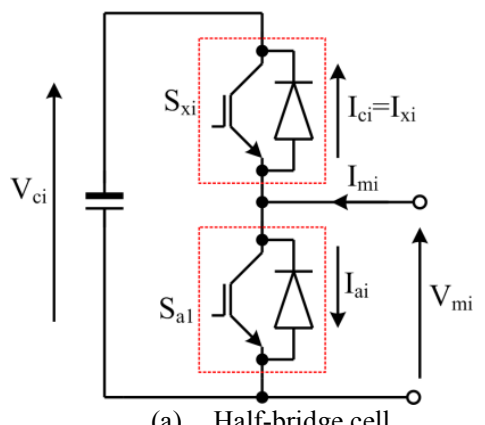

(a) Half-bridge cell

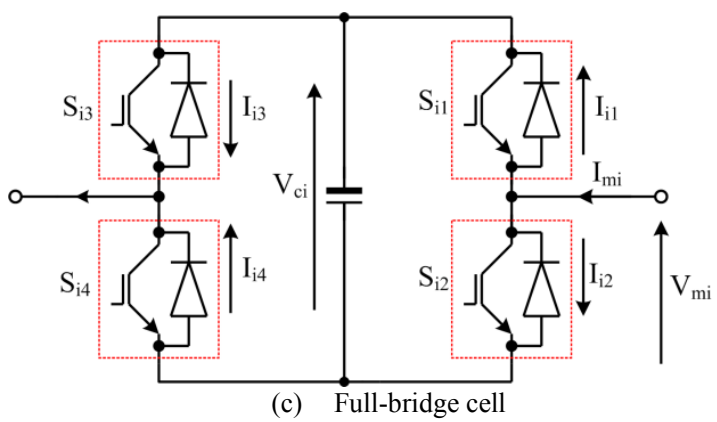

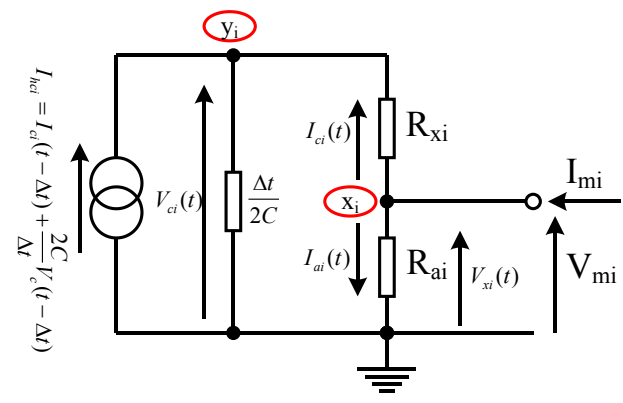

(b) Dommel electromagnetic transient representation of the halfbridge cell

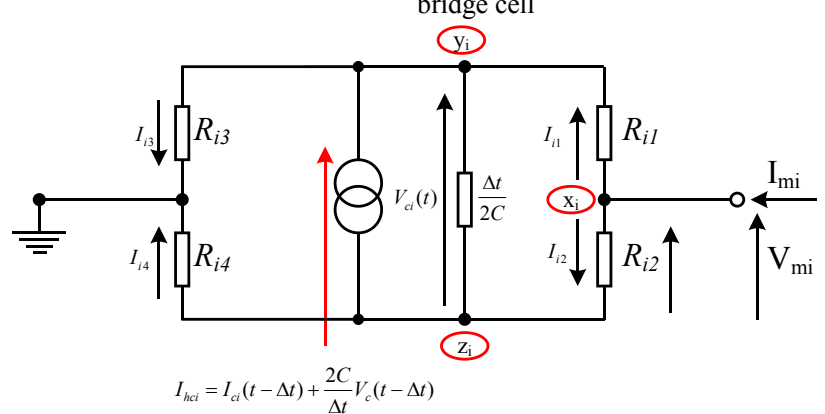

(d) Dommel's electromagnetic transient representation of the fullbridge MMC cell 
This paper is a postprint of a paper submitted to and accepted for publication in IEEE Journal of Emerging and Selected Topics in Power Electronics and is subject to Institution of Electrical and Electronic Engineering Copyright. The copy of record is available at IEEE Xplore Digital Library

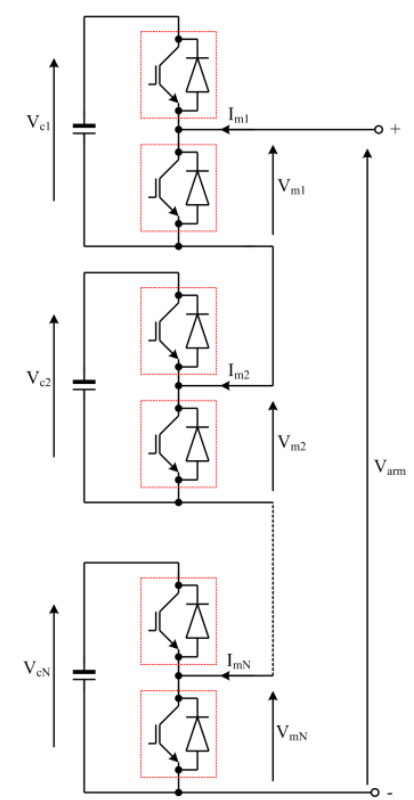

(e) One arm of the generic modular multilevel converter

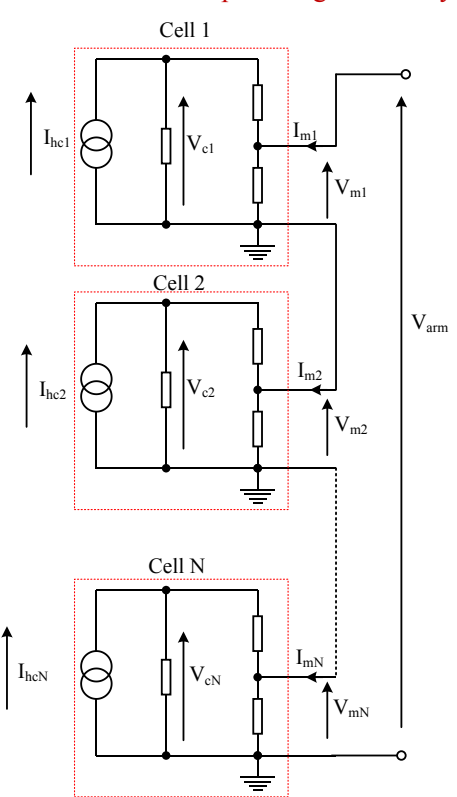

(f) Dommel electromagnetic transient representation of the generic modular multilevel converter arm

Figure 2: Cell and arm of the generic modular multilevel converter and their Dommel electromagnetic transient representation

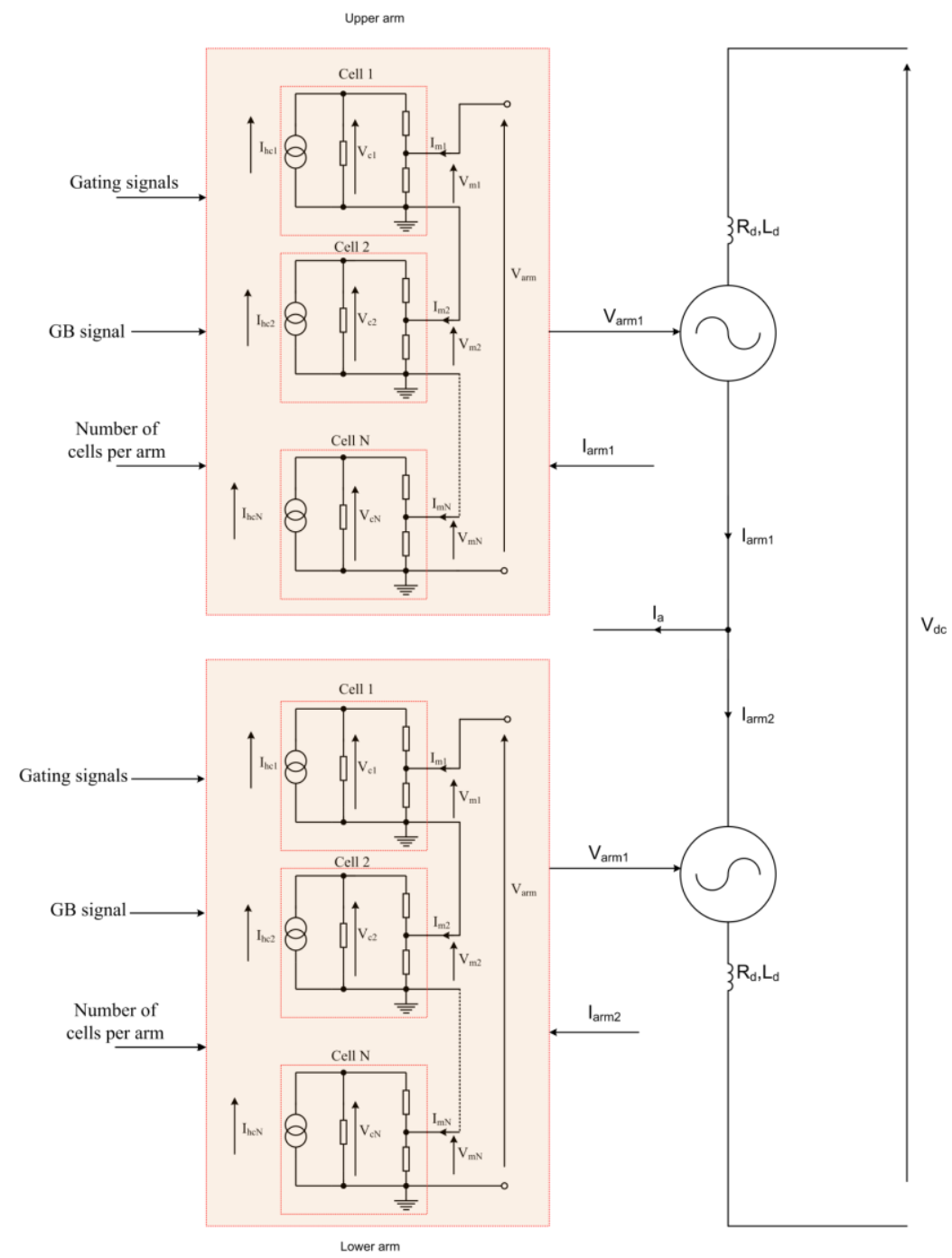

Figure 3: Illustration of the interfacing of the electromagnet transient model of the modular converter arms to SimPower System building blocks on a singlephase 
This paper is a postprint of a paper submitted to and accepted for publication in IEEE Journal of Emerging and Selected Topics in Power Electronics and is subject to Institution of Electrical and Electronic Engineering Copyright. The copy of record is available at IEEE Xplore Digital Library

\section{MODEL VALIDATION}

This section presents a validation of the generalized electromagnetic transient model of the MMC discussed in section III-A against its switching counterpart. In this validation, both models are built in Simulink; use the same circuit parameters shown in Table 1, and generalized modulator based on staircase modulation and capacitor voltage balancing; and proportional-integral controller for suppression of the arm currents $2^{\text {nd }}$ harmonic. For validation only, both models are operated in open load at 0.8 modulation using sinusoidal references. Figure 4 display simulation waveforms obtained from both models. Figure 4 (a), (b) and (c) show prefilter phase and line-to-line voltages at converter terminal, and three-phase load currents that obtained from MMC EMT model superimposed over that obtained from the MMC switching model, and observe that both model agree to smallest details as seen from the ac side. Figure 4 (d) and (e) present upper and lower arms cell capacitor voltages obtained from MMC switching and EMT models, and observe that both results are identical. Figure 4 (f) shows the sample of the upper and lower arm currents obtained from both models are identical as they coincide to microscopic level. Despite the level of agreements shown in Figure 4 (a) to (f), sample of the

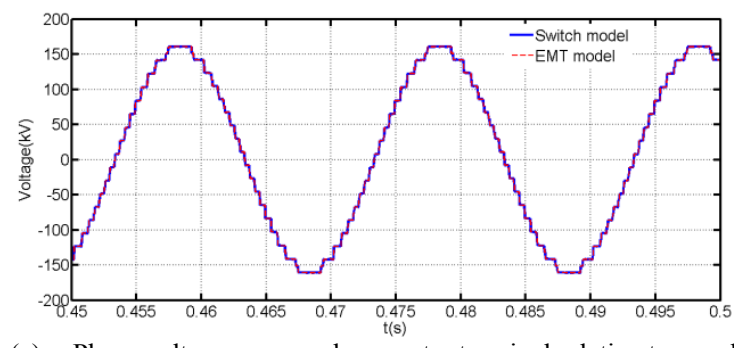

(a) Phase voltage measured converter terminal relative to supply midpoint (switch model superimposed on that obtained from EMT model)

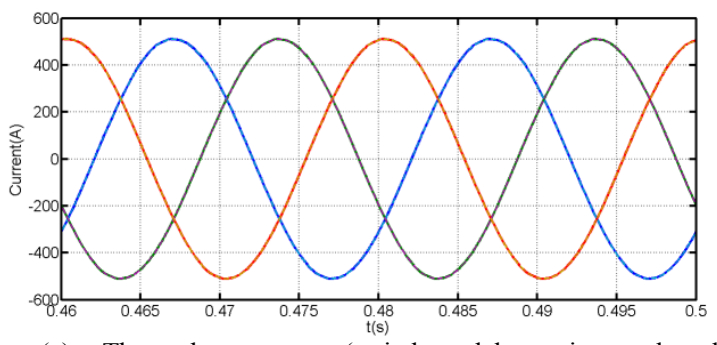

(c) Three-phase currents (switch model superimposed on that obtained from EMT model)

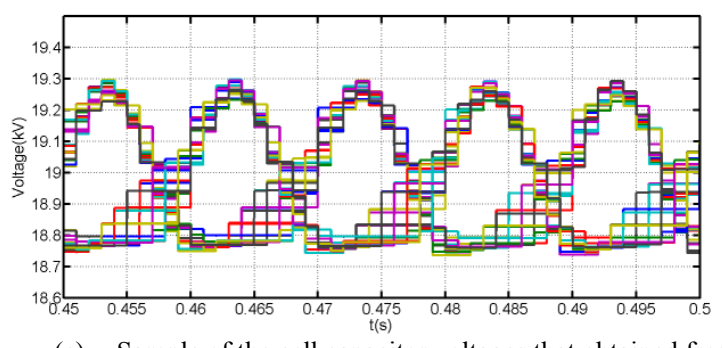

(e) Sample of the cell capacitor voltages that obtained from electromagnetic transient model common-mode current of the phase 'a' that obtained as $i_{a 1}+i_{a 2}$ from the MMC switching and EMT models shows high level of agreement, with noticeable minor differences between the results of the two models. Based on these results it can be concluded that the presented EMT model of the MMC is sufficiently accurate since it is able to match its switching counterpart in every details to microscopic level. This validation is carried out when both models are simulated in discrete domain, with $5 \mu$ s time step, and cell capacitor voltage measurements for the capacitor voltage balancing are updated on regular space of $500 \mu \mathrm{s}$. Further validations of the presented EMT model versus its detailed switching counterpart during ac and dc faults are presented in the appendix.

Table 1: Summary of converter parameters used for validation

\begin{tabular}{|l|l|}
\hline Parameter & Value \\
\hline dc link voltage $\mathrm{V}_{\mathrm{dc}}(\mathrm{kV})$ & 400 \\
\hline cell capacitance $\mathrm{C}_{\mathrm{m}}(\mathrm{mF})$ & 1.4 \\
\hline arm inductance $\mathrm{L}_{\mathrm{d}}(\mathrm{mH})$ & 50 \\
\hline Arm inductance internal resistance $\mathrm{R}_{\mathrm{d}}(\Omega)$ & 0.1 \\
\hline Load resistance $\mathrm{R}_{\mathrm{L}}(\Omega)$ & 250 \\
\hline Load inductance $\mathrm{L}_{\mathrm{L}}(\mathrm{mH})$ & 597 \\
\hline Number of cell per arm $(\mathrm{N})$ & 21 \\
\hline
\end{tabular}

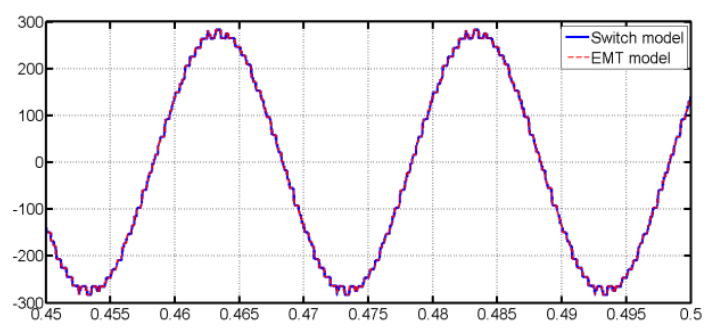

(b) Line-to-line voltage measured at converter terminal(switch model superimposed on that obtained from EMT model)

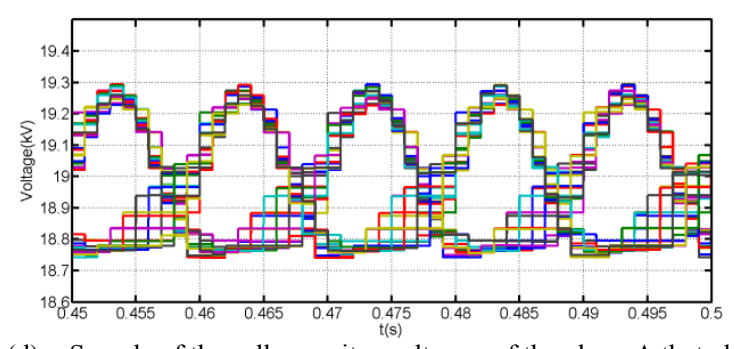

(d) Sample of the cell capacitor voltages of the phase A that obtained from switch model

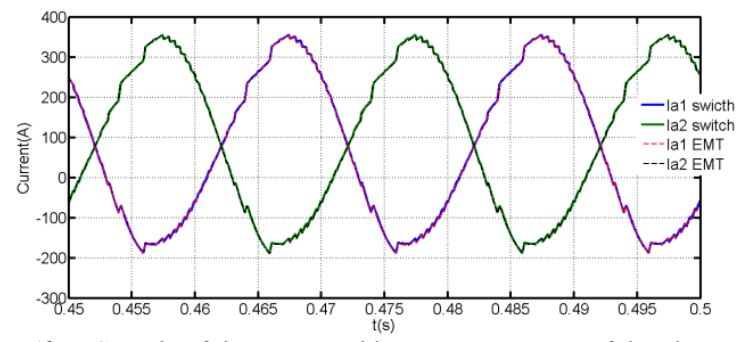

(f) Sample of the upper and lower arm currents of the phase A ( switch model superimposed on that obtained from EMT model) 
This paper is a postprint of a paper submitted to and accepted for publication in IEEE Journal of Emerging and Selected Topics in Power Electronics and is subject to Institution of Electrical and Electronic Engineering Copyright. The copy of record is available at IEEE Xplore Digital Library

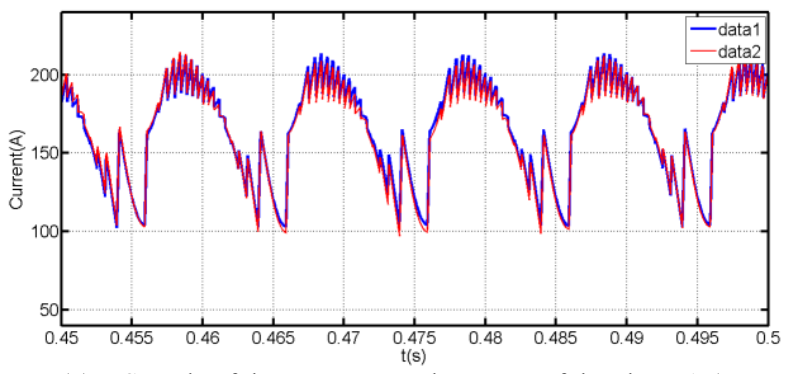

(g) Sample of the common mode current of the phase A $\left(I_{a l}+I_{a 2}\right)$

Figure 4: Waveforms presented aim to validate the MMC generalized model based on electromagnetic transient simulation approach against switch model that uses Simulink power electronics building blocks from SimPowerSystems library

In attempt to illustrate the scalability of the full-bridge model redundancies offered by the bi-polar capability of the fullpresented in this paper while restraining paper length, only bridge cells that have been used to maintain cell capacitor sample results obtained from open loop operation of a single- voltage, and reduce the cell capacitance size. Additionally, it phase full-bridge MMC with 51 and 301 cells per arm, must be noticed that the switching devices $\mathrm{S}_{\mathrm{a} 12}$ and $\mathrm{S}_{\mathrm{a} 13}$ are $\pm 320 \mathrm{kV}$ dc link voltage, 0.8 modulation index, and $300 \Omega$ and used only to balance the capacitor voltages using redundant $690 \mathrm{mH}$ load are presented. Figure 5 presents selected switch states that permit insertion of some the cell capacitor waveforms obtained when number of cells per arm is 51. with the opposite polarities when synthesizing intermediate Figure 5 (a) and (b) samples of the phase and line voltage voltage levels between $1 / 2 V_{d c}$ and $-1 / 2 V_{d c}$. This indicates that the obtained with 51 full-bridge cells per arm, and observe that usage of switching devices $S_{a 11}$ and $S_{a 14}$ are much higher than the converter being studied generates nearly pure sinusoidal that of the $S_{a 12}$ and $S_{a 13}$, hence higher rated heat sinks may be output with only 51 cells per arm. This clearly justifies the required for $S_{a 11}$ and $S_{a 14}$.

reduced cell approach adopted in cascaded two-level converter The results obtained when number of cells per is increased to presented in [53] that significantly reduces the complexity of 301 per arm are presented in Figure 6. Figure 6 (a) and (b) the power circuit and modulation. Figure 5 (c) shows the show the phase voltage obtained with 301 cells per arm is pure upper and lower arm currents obtained for phase ' $a$ ', and sinusoidal, and cell capacitor voltages of the upper and lower notice that with the suppression of the $2^{\text {nd }}$ harmonic in the arm arms are maintained tightly around $2.13 \mathrm{kV}$ as anticipated. currents, the upper and lower arm currents $\left(i_{a 1}\right.$ and $\left.i_{a 2}\right)$ tend be Figure 6 (c) shows the upper and lower arm currents are pure dominated by the fundamental plus dc components, which are sinusoidal plus dc components. The samples of the currents in responsible from the power transfer between converter ac and the switching devices of one full-bridge MMC cell in Figure 6 dc sides. Figure 5 (d) shows the voltage balance of the cell (d) and (e) show the switching frequency per device is not capacitor voltages of the upper and lower arms are maintained significantly reduced despite large increase in the number of tightly around $V_{d c} / N(640 \mathrm{kV} / 51 \approx 12.55 \mathrm{kV})$. Figure $5(\mathrm{c})$ to $(\mathrm{h})$ cells per arm compared to the case presented in Figure 5 (e) samples of the currents in the switching devices of one full- and (g). Based on the results presented in Figure 5 and Figure bridge MMC cell (top cell of the upper arm). Observe that the 6 , it can be concluded that the presented model in III-B is able switching devices of the full-bridge cells MMC operate more to reproduce the typical behaviour full-bridge MMC in similar frequently compared to that of the half-bridge cells MMC as way of traditional switching model.

will be shown later. This is due to exploitation of the extra

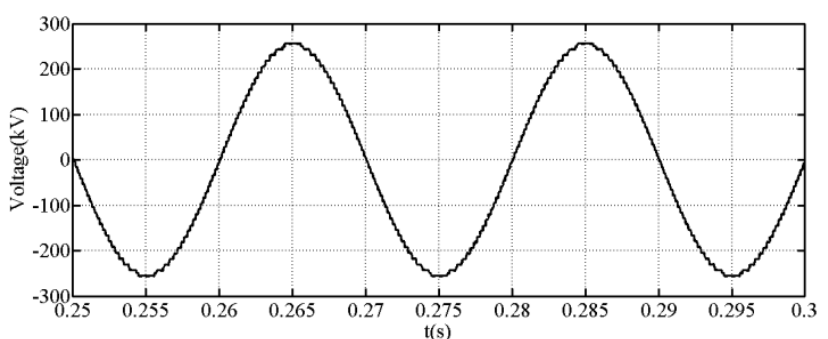

(a) Full-bridge MMC output phase relative to dc link mid-point

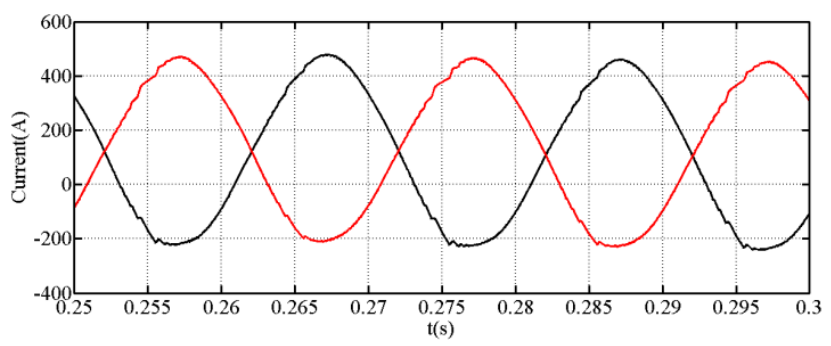

(c) Current waveforms in the upper and lower arms of the full-bridge $\mathrm{MMC}$

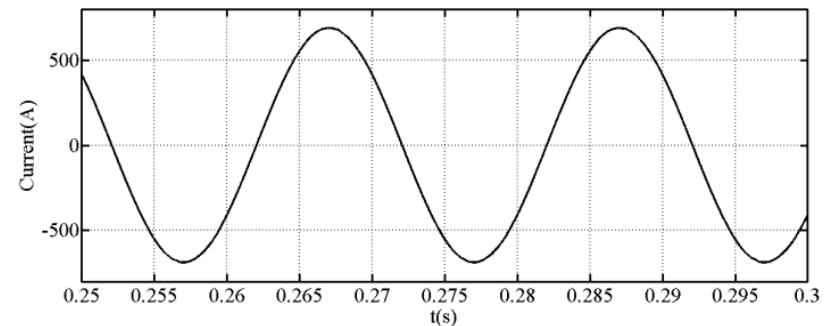

(b) Output phase current

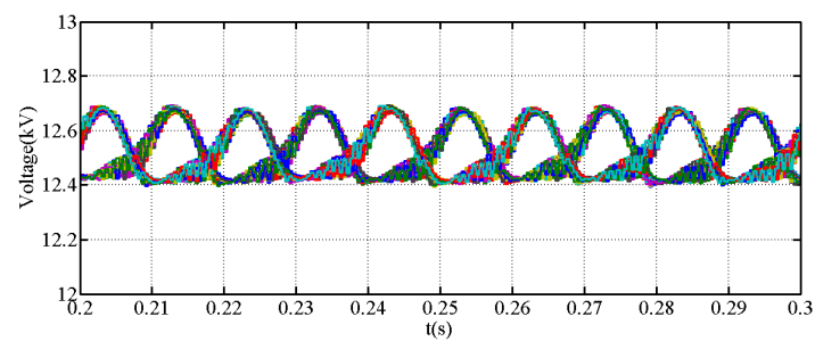

(d) Cell capacitor voltages of the upper and lower arms 
This paper is a postprint of a paper submitted to and accepted for publication in IEEE Journal of Emerging and Selected Topics in Power Electronics and is subject to Institution of Electrical and Electronic Engineering Copyright. The copy of record is available at IEEE Xplore Digital Library

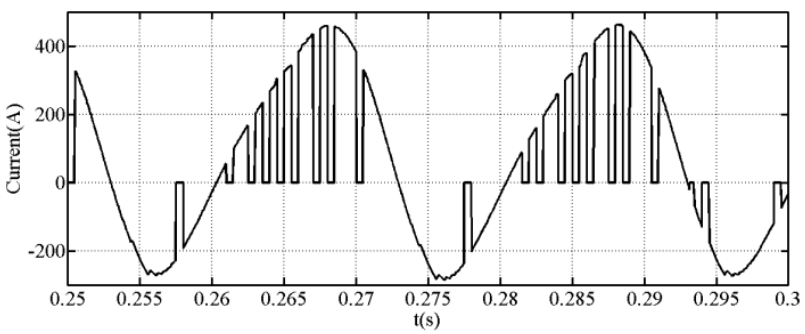

(e) Current in switching device $\left(\mathrm{S}_{\mathrm{a} 11}\right)$

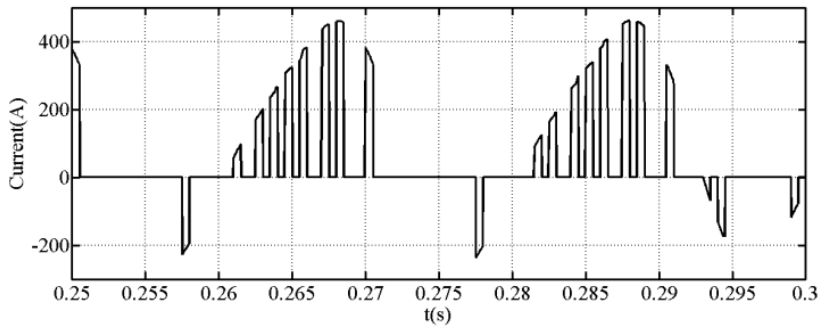

(g) Current in switching device $\left(\mathrm{S}_{\mathrm{a} 13}\right)$

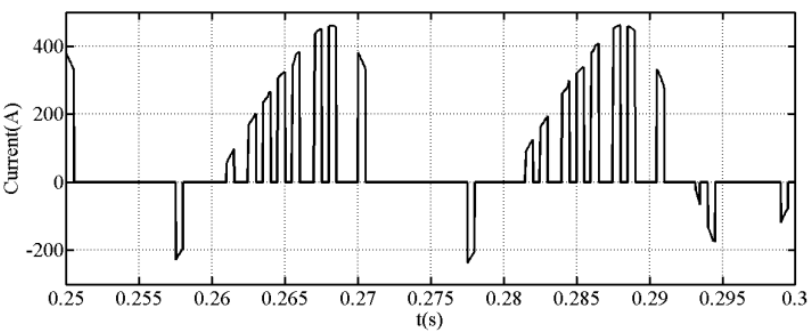

(f) Current in switching device $\left(\mathrm{S}_{\mathrm{a} 12}\right)$

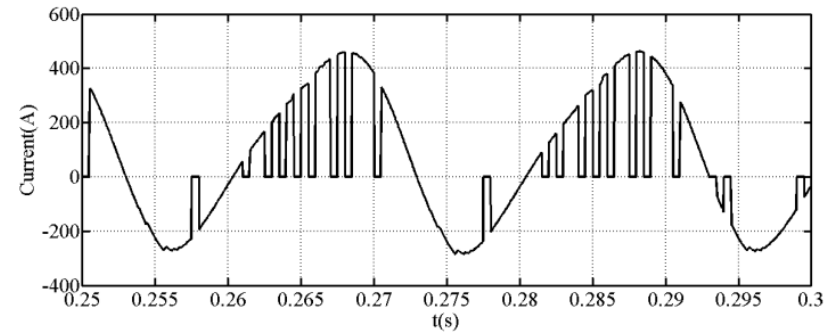

(h) Current in switching device $\left(\mathrm{S}_{\mathrm{a} 14}\right)$

Figure 5: Waveforms obtained from EMT model of the full-bridge MMC discussed in section III-B, with 51 cells per arm when $2^{\text {nd }}$ harmonic suppression of the arm currents controller is incorporated (cell capacitance $=5 \mathrm{mF}, \mathrm{R}_{\mathrm{d}}=0.05 \Omega$ and $\mathrm{L}_{\mathrm{d}}=50 \mathrm{mH}$ )

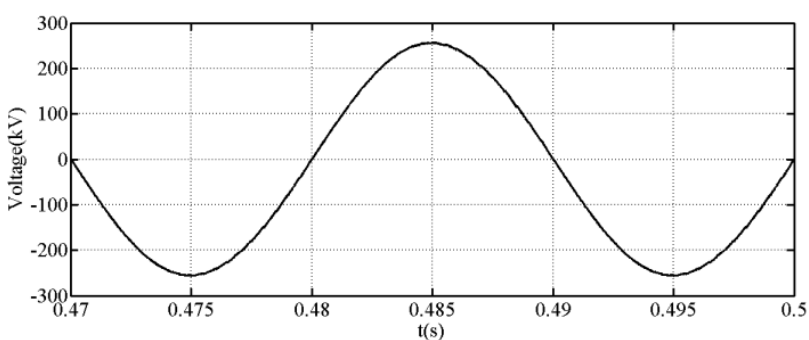

(a) Full-bridge MMC output phase voltage

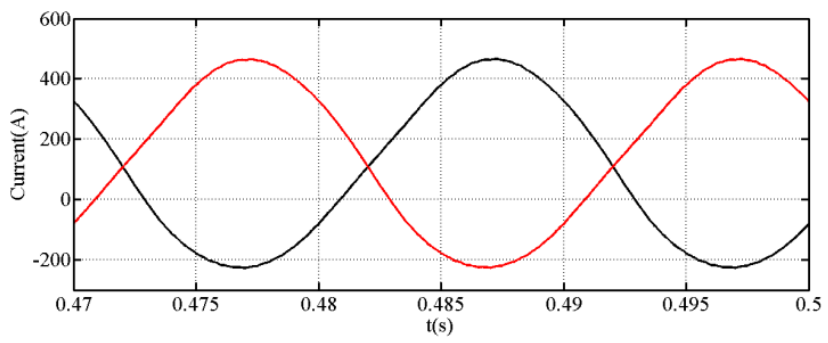

(c) Upper and lower arm currents

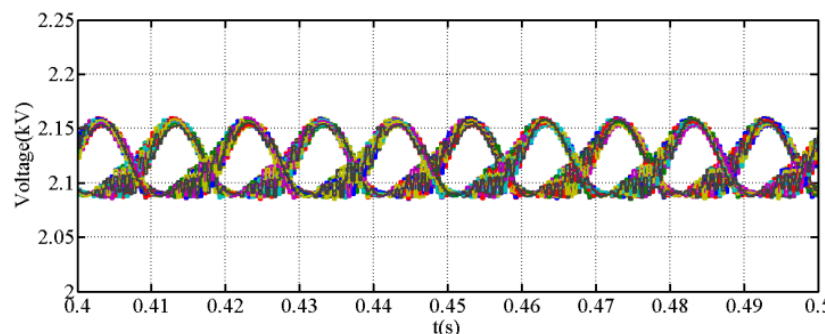

(b) Cell capacitor voltages

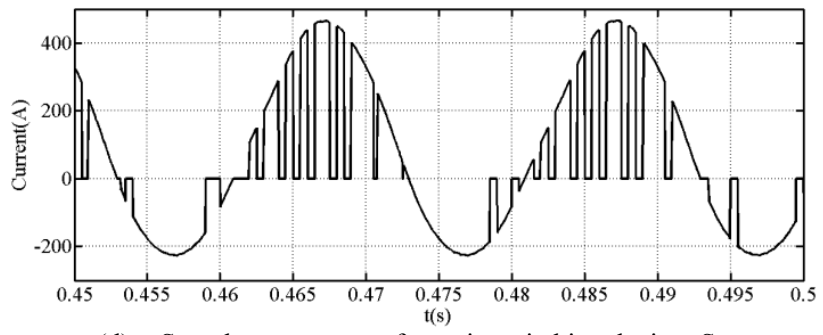

(d) Sample current waveforms in switching devices $S_{a 11}$

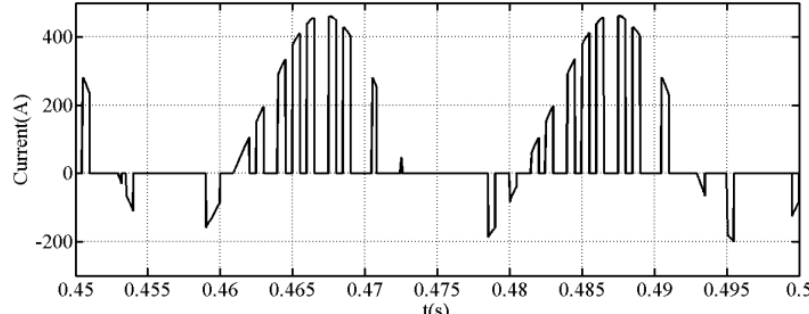

(e) Sample current waveforms in switching devices $\mathrm{S}_{\mathrm{a} 13}$

Figure 6: Waveforms obtained from EMT model of the full-bridge MMC discussed in section III-B, with 301 cells per arm and $2^{\text {nd }}$ harmonic suppression of the arm currents controller is incorporated (cell capacitance $=14 \mathrm{mF}, \mathrm{R}_{\mathrm{d}}=0.05 \Omega$ and $\mathrm{L}_{\mathrm{d}}=50 \mathrm{mH}$ )

\section{Control Systems Design}

For the purpose of the control design, considers the simplified representation of the grid connected modular multilevel converter in Figure 7, where ' $\mathrm{o}$ ' represents the ground (dc link mid-point of the symmetrical mono-polar as normally set by the stray capacitance of the dc line). Considering the upper and lower arms of the generic modular converter in Figure 7 when the total voltage developed across the upper and lower arms are replaced by their low-frequency components, the following equations are obtained for phase ' $a$ ':

$$
\begin{aligned}
& \frac{1}{2} V_{d c}-v_{a o}-R_{d} i_{a 1}-L_{d} \frac{d i_{a 1}}{d t}-v_{a 1}=0 \\
& \frac{1}{2} V_{d c}+v_{a o}-R_{d} i_{a 2}-L_{d} \frac{d i_{a 2}}{d t}-v_{a 2}=0
\end{aligned}
$$

Converter terminal voltage $v_{a o}$ can be expressed in terms of output current $i_{a}$ and grid voltage $v_{g a}$ as: 
This paper is a postprint of a paper submitted to and accepted for publication in IEEE Journal of Emerging and Selected Topics in Power Electronics and is subject to Institution of Electrical and Electronic Engineering Copyright. The copy of record is available at IEEE Xplore Digital Library

$$
v_{a o}=R_{T} i_{a}+L_{T} \frac{d i_{a}}{d t}+v_{g a}
$$

After subtracting (11) from (10) and combine with (12), the reference frame as:

following equation is obtained:

$$
\begin{aligned}
& v_{a 2}-v_{a 1}-R_{d}\left(i_{a 1}-i_{a 2}\right)-L_{d} \frac{d}{d t}\left(i_{a 1}-i_{a 2}\right) \\
& -2 R_{T} i_{a}-2 L_{T} \frac{d i_{a}}{d t}-2 v_{g a}=0
\end{aligned}
$$

Recall that $i_{a}=i_{a 1}-i_{a 2} \quad, \quad v_{a 1}=\frac{1}{2} V_{c}[1-m \sin (\omega t+\delta)]$ and For current control design, equation (16) is re-arranged as: $v_{a 2}=\frac{1}{2} V_{c}[1+m \sin (\omega t+\delta)]$, where $V_{c}$ presents the mean $\mathrm{dc}$ voltage of the upper and lower arms cell capacitors, $\mathrm{m}$ is the modulation index, $v_{g a}$ is the grid voltage, and $\delta$ is the angle between converter terminal $v_{a o}$ and grid voltage $v_{g a}$. With these assumptions, equation (13) can be reduced to:

$$
\left(\frac{1}{2} L_{d}+L_{T}\right) \frac{d i_{a}}{d t}+\left(\frac{1}{2} R_{d}+R_{T}\right) i_{a}=\frac{1}{2} m V_{c} \sin (\omega t+\delta)-v_{g a}
$$

From (14), differential equations that describe fundamental currents for all three phases in the modular converter can be deduced as:

$$
\begin{aligned}
& \left(\frac{1}{2} L_{d}+L_{T}\right) \frac{d i_{a}}{d t}+\left(\frac{1}{2} R_{d}+R_{T}\right) i_{a}=\frac{1}{2} m V_{c} \sin (\omega t+\delta)-v_{g a} \\
& \left(\frac{1}{2} L_{d}+L_{T}\right) \frac{d i_{b}}{d t}+\left(\frac{1}{2} R_{d}+R_{T}\right) i_{b}=\frac{1}{2} m V_{c} \sin \left(\omega t+\delta+\frac{4}{3} \pi\right)-v_{g b} \\
& \left(\frac{1}{2} L_{d}+L_{T}\right) \frac{d i_{c}}{d t}+\left(\frac{1}{2} R_{d}+R_{T}\right) i_{c}=\frac{1}{2} m V_{c} \sin \left(\omega t+\delta+\frac{2}{3} \pi\right)-v_{g c} \\
& \frac{d}{d t}\left[\begin{array}{c}
i_{d} \\
\lambda_{d} \\
i_{q} \\
\lambda_{q}
\end{array}\right]=\left[\begin{array}{ccc}
-\frac{\left(\frac{1}{2} R_{d}+R_{T}+k_{p}\right)}{\left(\frac{1}{2} L_{d}+L_{T}\right)} & \frac{1}{\left(\frac{1}{2} L_{d}+L_{T}\right)} & 0 \\
-k_{i} & 0 & 0 \\
0 & 0 & -\frac{\left(\frac{1}{2} R_{d}+R_{T}+k_{p}\right)}{\left(\frac{1}{2} L_{d}+L_{T}\right)} \\
0 & 0 & -k_{i}
\end{array}\right.
\end{aligned}
$$

$$
\begin{aligned}
\frac{d i_{d}}{d t}=- & \frac{\left(\frac{1}{2} R_{d}+R_{T}\right)}{\left(\frac{1}{2} L_{d}+L_{T}\right)} i_{d}+\frac{v_{c d}-v_{g d}+\omega\left(\frac{1}{2} L_{d}+L_{T}\right) i_{q}}{\left(\frac{1}{2} L_{d}+L_{T}\right)} \\
& \frac{d i_{q}}{d t}=-\frac{\left(\frac{1}{2} R_{d}+R_{T}\right)}{\left(\frac{1}{2} L_{d}+L_{T}\right)} i_{q}+\frac{v_{c q}-v_{g q}-\omega\left(\frac{1}{2} L_{d}+L_{T}\right) i_{d}}{\left(\frac{1}{2} L_{d}+L_{T}\right)}
\end{aligned}
$$

With the following change of variables: $u_{d}=v_{c d}-v_{g d}+\omega\left(\frac{1}{2} L_{d}+L_{T}\right) i_{q}$ and $u_{q}=v_{c q}-v_{g q}-\omega\left(\frac{1}{2} L_{d}+L_{T}\right) i_{d}, \quad u_{d}$ and $u_{q}$ are obtained by forcing $i_{d}$ and $i_{q}$ to follow $i_{d}^{*}$ and $i_{q}^{*}$ using proportional-integral controller as: $u_{d}=k_{p}\left(i_{d}^{*}-i_{d}\right)+k_{i} \int\left(i_{d}^{*}-i_{d}\right) d t$ and $u_{q}=k_{p}\left(i_{q}^{*}-i_{q}\right)+k_{i} \int\left(i_{q}^{*}-i_{q}\right) d t$ where $k_{p}$ and $k_{i}$ represent the proportional and integral gains. After manipulations of equations (17) and (18), and definitions given for $u_{d}$ and $u_{q}$, where the integral parts of $u_{d}$ and $u_{q}$ are replaced by $\lambda_{d}$ and $\lambda_{q}$ the following equation is obtained:

After Laplace manipulation of (19), the initial gains of the equation (21) is written as in (22) and broken into (23) and inner current controller can be selected using (24): $k_{p}=2 \omega_{n} \zeta\left(\frac{1}{2} L_{d}+L_{T}\right)-\left(\frac{1}{2} R_{d}+R_{T}\right) \quad$ and $\quad k_{i}=\omega_{n}^{2}\left(\frac{1}{2} L_{d}+L_{T}\right)$, and natural frequency $\omega_{n}$ can be selected assuming settling time ' $\mathrm{T}_{\mathrm{s}}$ ' and damping factor ' $\zeta$ ' from $\omega_{n}=\frac{4}{\zeta T_{s}}$. However, the final gains must be fined tune to ensure that satisfactory performance is achieved over the entire system operating range, including ac and dc network faults. From definitions of the $u_{d}$ and $u_{q}$, where $u_{d}$ and $u_{q}$ are the outputs of current
controller in the $\mathrm{d}$ and $\mathrm{q}$ channels, the block diagram for the inner current controller in Figure 8 is obtained.

For design of the supplementary current controller that responsible for suppression of the $2^{\text {nd }}$ harmonic component of
the common mode current, add equations (10) and (11), and the following equation is obtained:

$$
V_{d c}-\left(v_{a 1}+v_{a 2}\right)-R_{d}\left(i_{a 1}+i_{a 2}\right)-L_{d} \frac{d}{d t}\left(i_{a 1}+i_{a 2}\right)=0
$$

Recall that the common mode current of the upper and lower arms can be defined as $i_{c o m}=i_{a 1}+i_{a 2}$, therefore equation (20) can be reduced to:

$$
\frac{d i_{c o m}}{d t}=-\frac{R_{d}}{L_{d}} i_{c o m}+\frac{V_{d c}-V_{c}}{L_{d}}
$$

Since flow of the ac current components of the $i_{a 1}$ and $i_{a 2}$ in the arm reactors and cell capacitors cause capacitor voltages of the upper and lower arms to oscillate (thus, $V_{c}$ ), the common The voltage $v_{2 h}$ needed to minimize the $2^{\text {nd }}$ harmonic in the mode current $i_{\text {com }}$ contains dc and ac components. Therefore, MMC arm current is estimated from PI controller as:

$$
\begin{aligned}
& \frac{d i_{h}}{d t}\left(I_{d}+i_{h}\right)=-\frac{R_{d}}{L_{d}}\left(I_{d}+i_{h}\right)+\frac{1}{L_{d}}\left(V_{c 0}+v_{h}\right) \\
& \frac{d I_{d}}{d t}=-\frac{R_{d}}{L_{d}} I_{d}+\frac{1}{L_{d}} V_{c 0} \\
& \frac{d i_{h}}{d t}=-\frac{R_{d}}{L_{d}} i_{h}+\frac{1}{L_{d}} v_{h}
\end{aligned}
$$

Observe that equation (23) describes dynamics of the arm current dc component $I_{d}$, which is responsible for power transfer between converter and dc side. Equation (24) describes dynamics of the ac component of the common mode current $i_{h}$, which is dominantly $2^{\text {nd }}$ order harmonic plus other harmonics, depending on the modulation strategy employed; where $v_{h}$ represents the cell capacitor voltage ripple. In attempt to reduce the semiconductor losses due to $2^{\text {nd }}$ harmonic of the arm current, this paper favours the use of a simple PI controller over the proportional resonance to minimize $2^{\text {nd }}$ harmonics in the MMC arm currents (or $i_{h}$ ). This requires $i_{h}$ to be passed through a band pass filter (BPF), tuned at $100 \mathrm{~Hz}$ with high quality factor in order to extract only the $2^{\text {nd }}$ harmonic component $i_{2 h}$ from $i_{h}$. Considering $2^{\text {nd }}$ harmonic only, equation (24) becomes:

$$
\frac{d i_{2 h}}{d t}=-\frac{R_{d}}{L_{d}} i_{2 h}+\frac{1}{L_{d}} v_{2 h}
$$


This paper is a postprint of a paper submitted to and accepted for publication in IEEE Journal of Emerging and Selected Topics in Power Electronics and is subject to Institution of Electrical and Electronic Engineering Copyright. The copy of record is available at IEEE Xplore Digital Library

$$
v_{2 h}=\alpha_{p}\left(i_{2 h}^{*}-i_{2 h}\right)+\alpha_{i} \int\left(i_{2 h}^{*}-i_{2 h}\right) d t
$$

After replacing the integral part in (26) by $z_{2 h}$, and algebraic manipulations of (25) and (26), the following equation is obtained:

$$
\frac{d}{d t}\left[\begin{array}{c}
i_{2 h} \\
z_{2 h}
\end{array}\right]=\left[\begin{array}{cc}
-\left(R_{d}+\alpha_{p}\right) / L_{d} & 1 / L_{d} \\
-\alpha_{i} & 0
\end{array}\right]\left[\begin{array}{c}
i_{2 h} \\
z_{2 h}
\end{array}\right]+\left[\begin{array}{c}
\alpha_{p} / L_{d} \\
\alpha_{i}
\end{array}\right] i_{2 h}^{*}
$$

After Laplace manipulations of (27), the following closed loop transfer function for the $2^{\text {nd }}$ harmonic suppression is obtained:

$$
\frac{i_{2 h}(s)}{i_{2 h}^{*}(s)}=\frac{\alpha_{p} / L_{d} s+\alpha_{i} / L_{d}}{s^{2}+\left(\alpha_{p}+R_{d}\right) / L_{d} s+\alpha_{i} / L_{d}}
$$

From (28), the PI gains are : $\alpha_{p}=2 \zeta \omega_{n} L_{d}-R_{d}$ and $\alpha_{i}=\omega_{n}^{2} L_{d}$, where $\zeta$ and $\omega_{n}$ are damping factor and controller natural frequency in rad/s. To accommodate BPF dynamics and avoid interference with the main power flow controllers, the gains for the $2^{\text {nd }}$ harmonic suppression controller must be selected to be as slow as possible, and its output is limited to $5 \%$ of modulation index. This indicates that inclusion of such supplementary controller reduces converter dc link utilization and P-Q envelope if compared to the approach that uses passive filter for arm current $2^{\text {nd }}$ harmonic suppression as demonstrated in.[53, 62, 63]. Figure 8 summarises the overall control system that has been used in the $\mathrm{MMC}_{1}$ and $\mathrm{MMC}_{2}$,

which includes all expected HVDC basic controllers and supplementary controller for suppression of the arm currents $2^{\text {nd }}$ harmonic component.
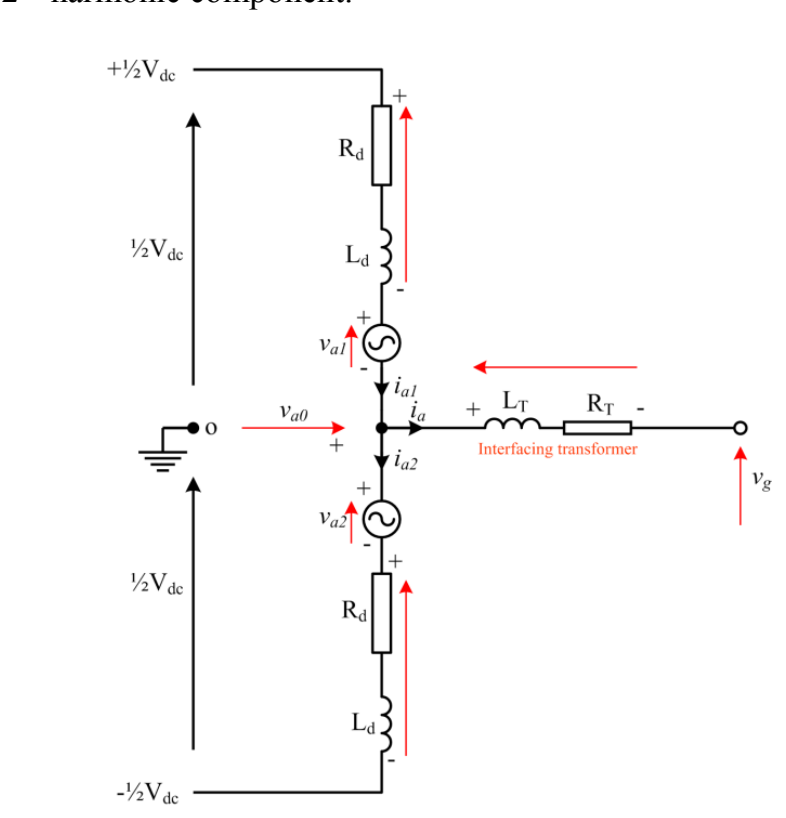

Figure 7: Simplified illustration of generic modular multilevel converter connected to grid

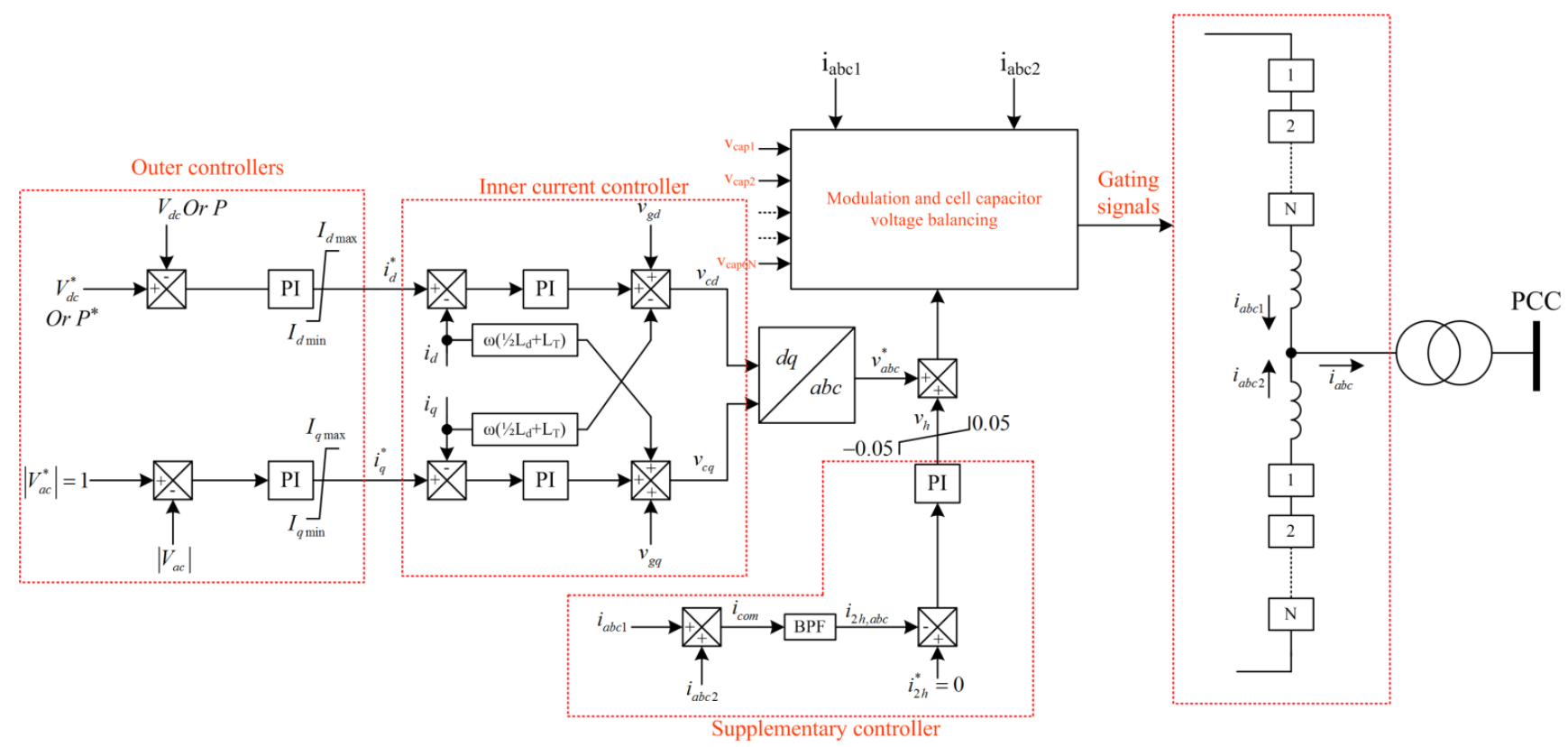

Figure 8: Block diagram illustrates generic control systems used in both converter stations $\mathrm{MMC}_{1}$ and $\mathrm{MMC}_{2}$

\section{SIMULATION OF FULL-SCALE HVDC LINK}

To demonstrate the effectiveness of the electromagnetic transient (EMT) modelling approach discussed in section III when used to simulate full-scale VSC-HVDC links, an example link in Figure 9 is built in Simulink environment with converter stations $\mathrm{MMC}_{1}$ and $\mathrm{MMC}_{2}$ modelled with 201 halfbridge cells per arm, with parameters listed in Table $2 . \mathrm{MMC}_{1}$ is configured to regulate active power exchange between $\mathrm{AC}$ systems 1 and 2, and provides voltage support at $\mathrm{PCC}_{1} \cdot \mathrm{MMC}_{2}$ regulates dc link voltage level at $400 \mathrm{kV}$ (pole-to-pole), and supports ac voltage at $\mathrm{PCC}_{2}$. Both $\mathrm{MMC}_{1}$ and $\mathrm{MMC}_{2}$ employ staircase modulation, with sinusoidal references. Small time step of $5 \mu \mathrm{s}$ is used throughout this section to show the computational efficiency of the presented MMC when simulating HVDC links with large number of cells per converter (1206 cells per converter, and 2412 cells per model). 
This paper is a postprint of a paper submitted to and accepted for publication in IEEE Journal of Emerging and Selected Topics in Power Electronics and is subject to Institution of Electrical and Electronic Engineering Copyright. The copy of record is available at IEEE Xplore Digital Library

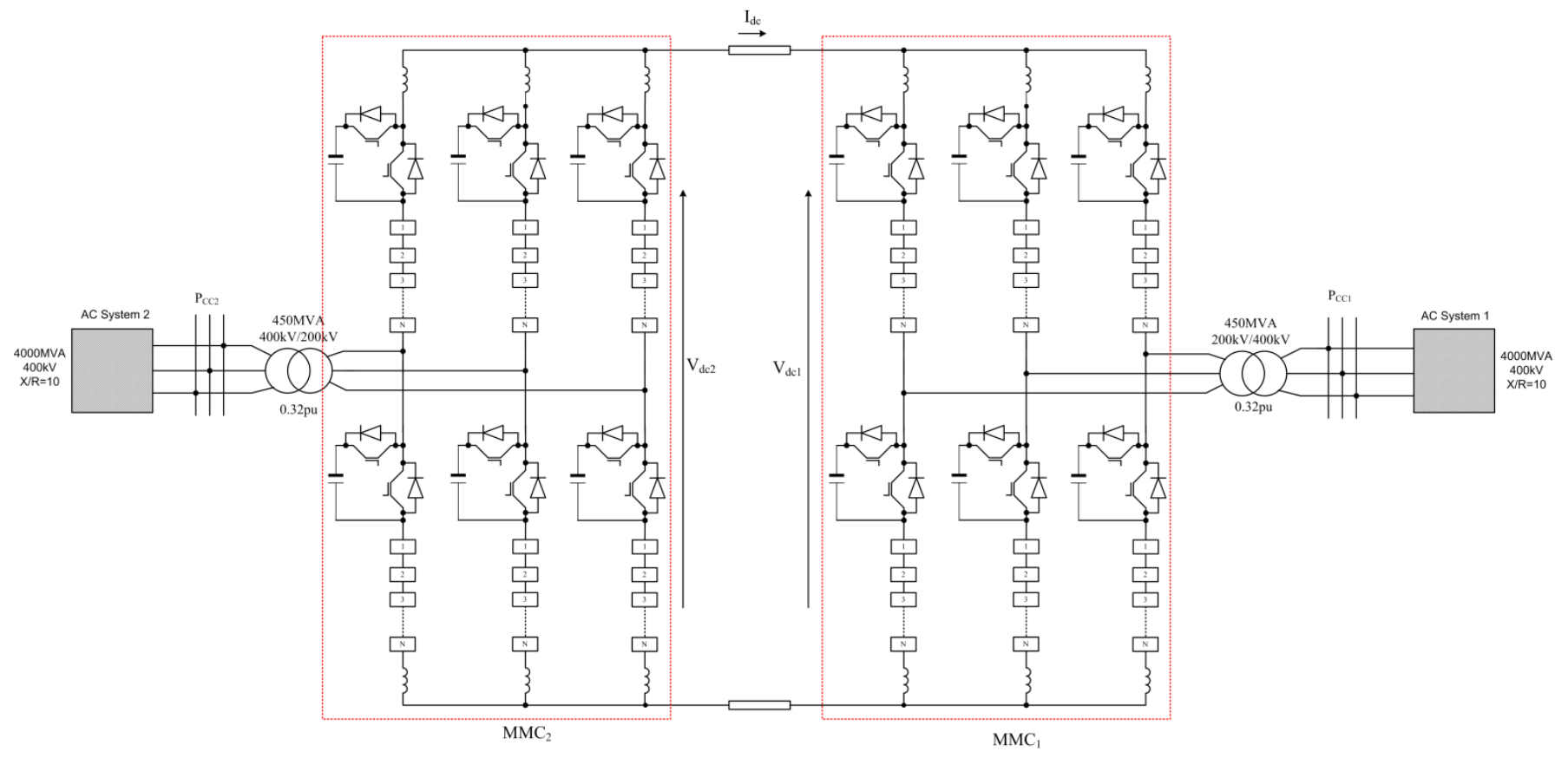

Figure 9: Simulink model of full-scale VSC-HVDC

Table 2: Parameters of the full-scale MMC based HVDC link in Figure 9

\begin{tabular}{|l|l|l|l|}
\hline Converters MMC1 and MMC2 & & interfacing transformer & $200 \mathrm{kV} / 400 \mathrm{kV}$ \\
\hline DC link voltage & $\pm 200 \mathrm{kV}$ & Interfacing transformer leakage reactance & $0.32 \mathrm{pu}$ \\
\hline Rated apparent power & $450 \mathrm{MVA}$ & Resistance of the interfacing transformer & $0.00015 \mathrm{pu}$ \\
\hline Maximum active power capability & $400 \mathrm{MW}$ & AC systems 1 and 2 & $4000 \mathrm{MVA}, 400 \mathrm{kV}$ and $\mathrm{X} / \mathrm{R}=10$ \\
\hline Maximum reactive power capability & $\pm 206 \mathrm{MVAr}$ & DC line resistance $\left(\mathrm{R}_{\mathrm{dc}}\right)$ & $10 \mathrm{~m} \Omega / \mathrm{km}$ \\
\hline Inductance of the arm reactor $\left(\mathrm{L}_{\mathrm{d}}\right)$ & $31 \mathrm{mH}$ & DC line capacitance $\left(\mathrm{C}_{\mathrm{dc}}\right)$ & $0.15 \mu \mathrm{F} / \mathrm{km}$ \\
\hline Resistance of the arm reactor $\left(\mathrm{R}_{\mathrm{d}}\right)$ & $0.015 \Omega$ & DC line inductance $\left(\mathrm{L}_{\mathrm{dc}}\right)$ & $0.6 \mathrm{mH} / \mathrm{km}$ \\
\hline Cell capacitance $(\mathrm{Cm})$ & $6 \mathrm{mF}$ & DC line length & $100 \mathrm{~km}$ \\
\hline Number of cells per arm & 201 & & \\
\hline
\end{tabular}

\section{A) Normal Operation}

$10(\mathrm{~g})$ and $(\mathrm{h})$ show dc link current, and converter line-to-line This section presents simulation results obtained when terminal voltage. Figure 10 (h) shows that with such large converter station $\mathrm{MMC}_{1}$ of the full-scale HVDC link in Figure number of cells, MMC presents pure sinusoidal voltage to the 9 ramps its output power from 0 to $0.7 \mathrm{pu}(315 \mathrm{MW})$ in order to interfacing transformer. Figure $10(\mathrm{i})$ and (j) show the de link export power from $a c$ system 2 to 1 . At time $\mathrm{t}=0.8 \mathrm{~s}, \mathrm{MMC}_{1}$ voltage of the $\mathrm{MMC}_{1}$ and $\mathrm{MMC}_{2}$. Figure $10(\mathrm{k})$ and (l) display reverses the power flow by gradually ramping down its output cell capacitor voltages of both converter stations, and observe power from $0.7 \mathrm{pu}$ to $-0.7 \mathrm{pu}$. Observe that the selected that they are balanced and settled around $1.99 \mathrm{kV}$ as expected. waveforms in Figure 10 reproduce the typical behaviour of the Figure 10(m) shows zoomed version of the cell capacitor MMC based HVDC link in great detail than similar works voltage of the $\mathrm{MMC}_{1}$, phase ' $a$ '. Figure 10 (n) and (o) present presented in [28, 30, 31]. Figure 10(a) and (b) show active and sample of the current waveforms in the switching devices of reactive power at ac sides of the $\mathrm{MMC}_{1}$ and $\mathrm{MMC}_{2}$. Figure one cell (top cell in the phase ' $a$ ' upper arm). The results in 10 (c) and (d), and (e) and (f) show ac current waveforms Figure 10 have shown that the presented modelling approach $\mathrm{MMC}_{1}$ and $\mathrm{MMC}_{2}$ inject into $\mathrm{PCC}_{1}$ and $\mathrm{PCC}_{2}$, and their arm is able to reproduce the typical behaviour of full-scale $\mathrm{MMC}$ currents. Notice that the shape of the arm currents in Figure 10 based HVDC link in great detail, including access to all (e) and (f) are typical to the SIEMENS HVDC PLUS internal variables of the modular converters which are of great presented in [64] as the power flow direction changes. Figure importance from system design prospective.

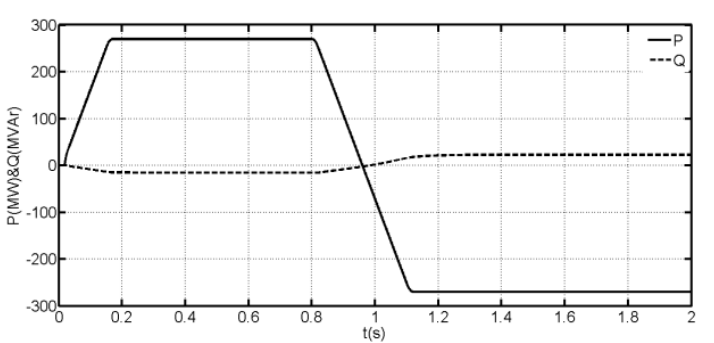

(a) Active and reactive power $\mathrm{MMC}_{1}$ exchanges with $\mathrm{PCC}_{1}$

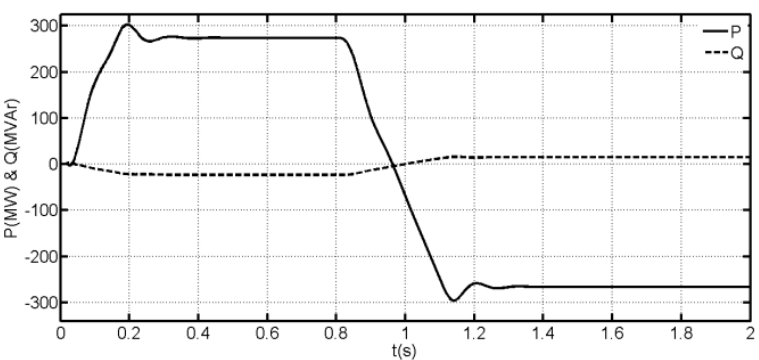

(b) Active and reactive power $\mathrm{MMC}_{2}$ exchanges with $\mathrm{PCC}_{2}$ 
This paper is a postprint of a paper submitted to and accepted for publication in IEEE Journal of Emerging and Selected Topics in Power Electronics and is subject to Institution of Electrical and Electronic Engineering Copyright. The copy of record is available at IEEE Xplore Digital Library

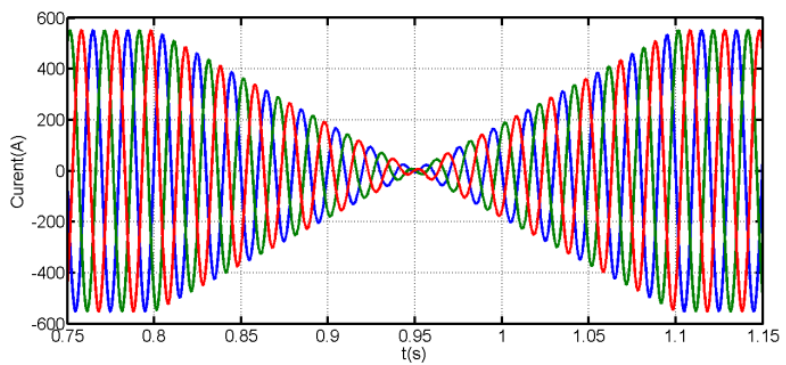

(c) Current waveforms $\mathrm{MMC}_{1}$ injects into $\mathrm{PCC}_{1}$

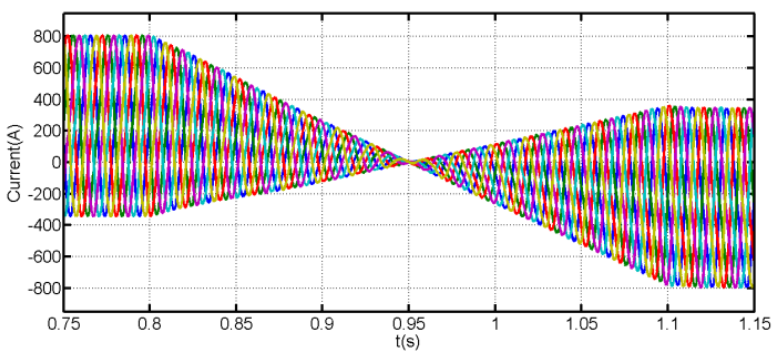

(e) $\mathrm{MMC}_{1}$ six arm currents zoomed around power reversal

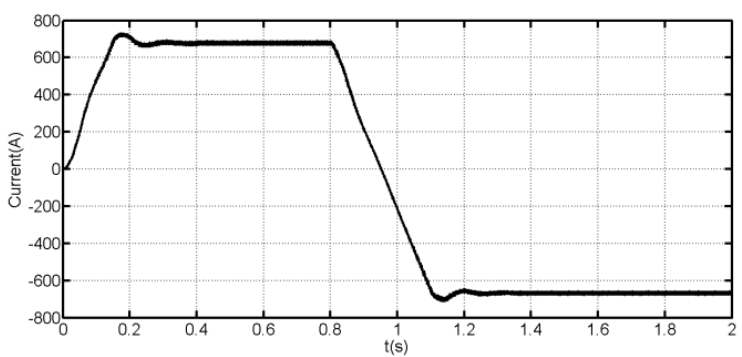

(g) DC link current

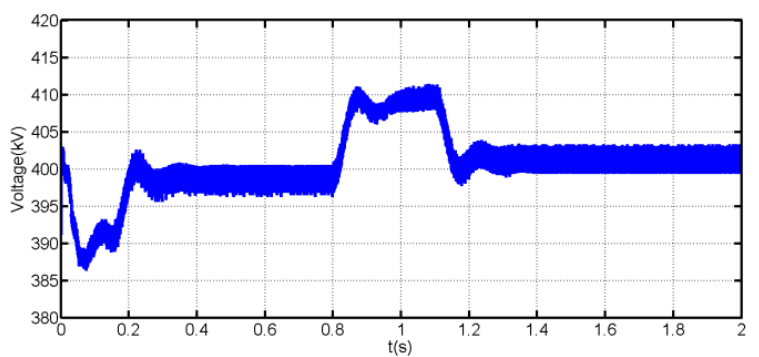

(i) $\mathrm{VSC}_{1} \mathrm{DC}$ link voltage

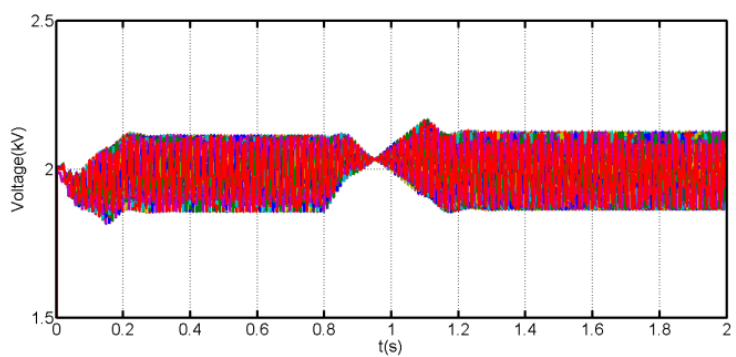

(k) Voltage across 402 cell capacitors of the $\mathrm{MMC}_{1}$ (phase A)

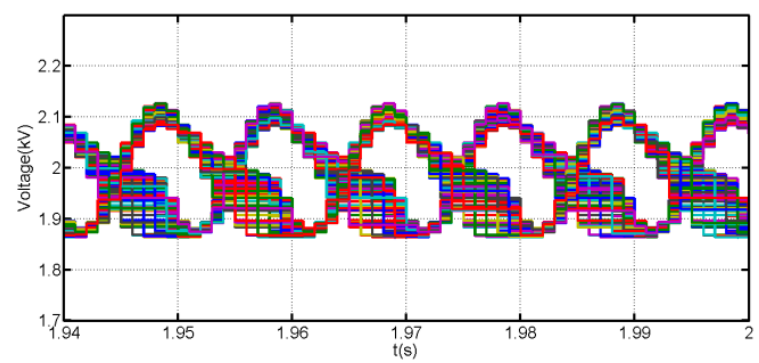

(m) Zoomed version of the 402 cell capacitors of the $\mathrm{MMC}_{1}$ (phase A)

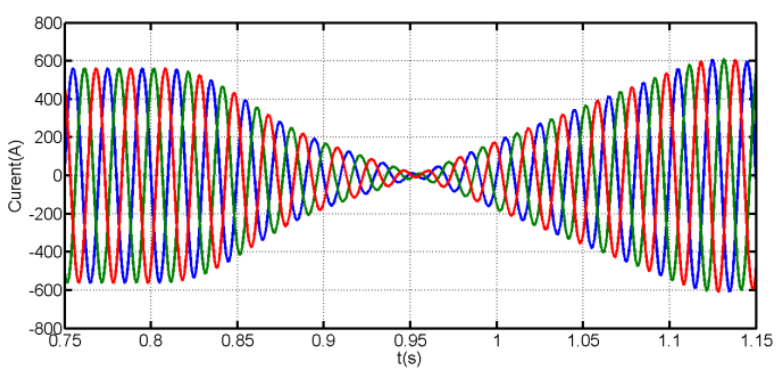

(d) Current waveforms $\mathrm{MMC}_{2}$ injects into $\mathrm{PCC}_{2}$

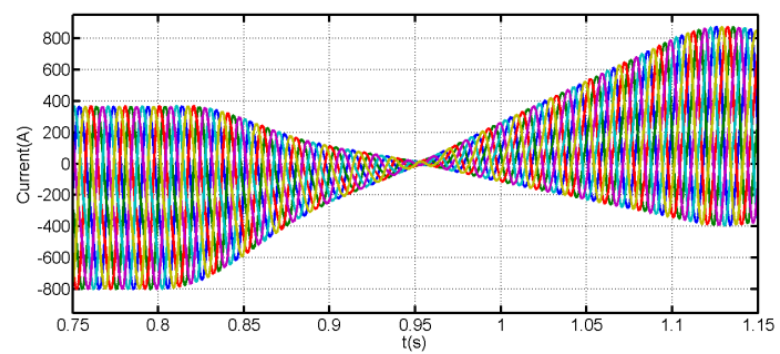

(f) $\quad \mathrm{MMC}_{2}$ six arm currents zoomed around power reversal

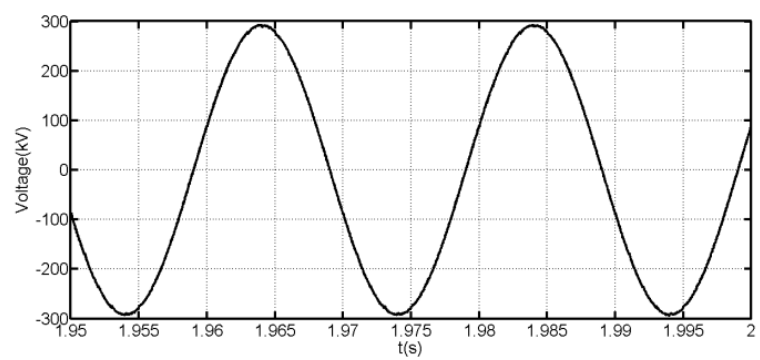

(h) Sample of the line-to-line voltage $\mathrm{MMC}_{1}$ presents to it interfacing transformer (measured at converter terminal before interfacing transformer)

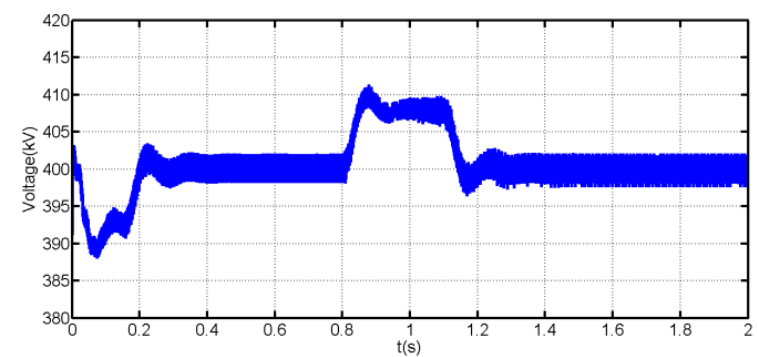

(j) $\mathrm{VSC}_{2} \mathrm{DC}$ link voltage

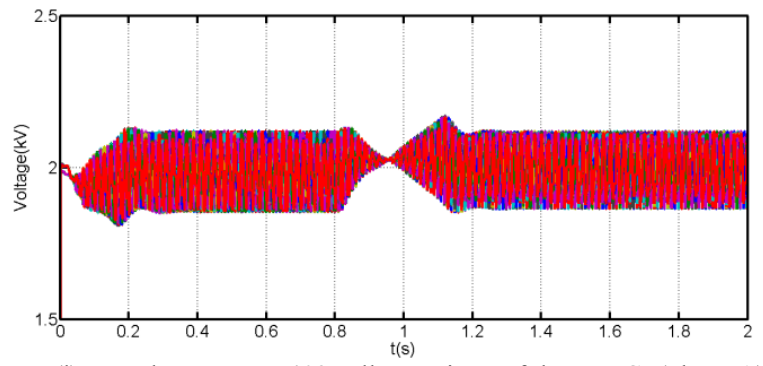

(l) Voltage across 402 cell capacitors of the $\mathrm{MMC}_{2}$ (phase A)

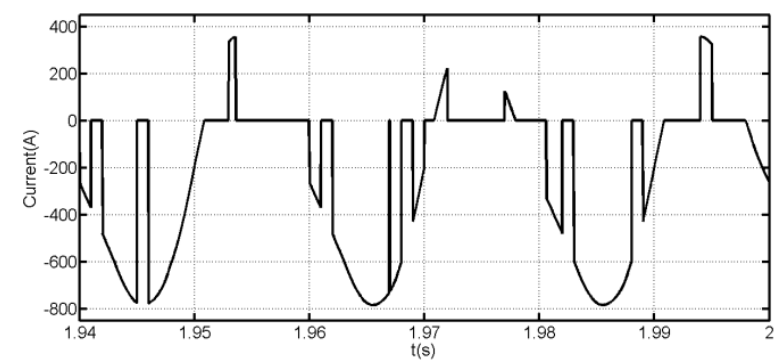

(n) Current in the swicthing device $\mathrm{S}_{\mathrm{a} 1}\left(\mathrm{MMC}_{1}\right)$ 
This paper is a postprint of a paper submitted to and accepted for publication in IEEE Journal of Emerging and Selected Topics in Power Electronics and is subject to Institution of Electrical and Electronic Engineering Copyright. The copy of record is available at IEEE Xplore Digital Library

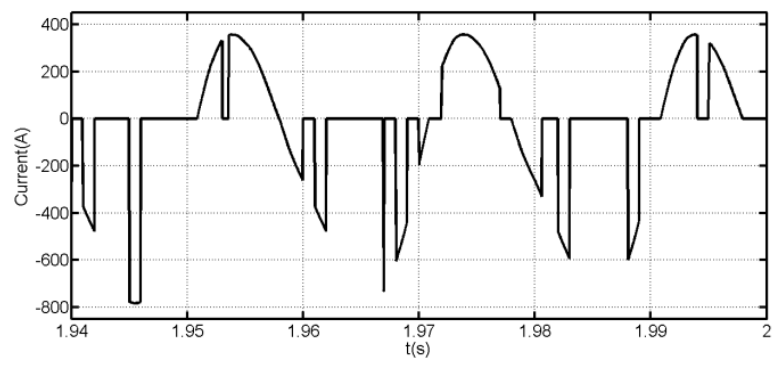

(o) Current waveform in the swicthing device $\mathrm{S}_{\mathrm{x} 1}\left(\mathrm{MMC}_{1}\right)$

Figure 10: Selected waveforms that demonstrate the suitability of the EMT approach discussed in section III for full-scale modelling of the MMC based VSCHVDC link

B) AC fault

converters. Figure 11 (c) and (d) show the voltage magnitude To examine the suitability of the presented MMC modelling and ac current waveforms at $\mathrm{PCC}_{1}$, and notice that although approach for studying ac network faults, the full-scale the voltage at $\mathrm{PCC}_{1}$ collapses to less than $30 \%$ of the rated Simulink model of the HVDC link in Figure 9 is subjected to a voltage, the current contribution of the $\mathrm{MMC}_{1}$ to the ac fault is three-phase ac fault at $\mathrm{PCC}_{1}$, through $2 \Omega$ fault resistance at limited and less than the pre-fault currents. The dc link time $\mathrm{t}=0.4 \mathrm{~s}$ and cleared after $200 \mathrm{~ms}$. After ac fault is detected, voltages of the $\mathrm{MMC}_{1}$ and $\mathrm{MMC}_{2}$ in Figure 11 (e) and (f) $\mathrm{MMC}_{1}$ active output is reduced immediately to 0 and restored exhibit slight increase during brief period of ac and dc powers when the fault is cleared. Figure 11 displays selected mismatch as a result of ac fault and sudden reduction in waveforms obtained from the full-scale Simulink model when $\mathrm{MMC}_{1}$ power order; thanks to the large energy storage it is subjected to a three-phase fault at $\mathrm{PCC}_{1}$. Figure 11 (a) and capacity of 1206 cell capacitors per converter. Figure 11 (g) (b) show active and reactive powers $M M C_{1}$ and $M M C_{2}$ and $(\mathrm{h})$ show the cell capacitor voltages of the $\mathrm{MMC}_{1}$ and exchange with their point of common couplings $\mathrm{PCC}_{1}$ and $\mathrm{MMC}_{2}$ experience some disturbances during ac fault, with the $\mathrm{PCC}_{2}$. Observe that although the active power of the $\mathrm{MMC}_{1}$ is cell capacitor voltages of the $\mathrm{MMC}_{1}$ (near to the fault) reduced to zero immediately when ac fault is detected, the experience larger voltage ripples than that of the $\mathrm{MMC}_{2}$ active power at the ac side of the $\mathrm{MMC}_{2}$ that regulates dc link (remote converter). These results have demonstrated the voltage takes longer time to fall to zero. This is because the ability of the presented model to capture the behaviour of dynamics of the dc power (or dc component of the arm typical MMC based HVDC link, including internal converter currents) is strongly link to the change in the cell voltages, station dynamics and interactions between ac and dc sides. which take several fundamental cycles to adjust following Therefore, it can be concluded that the presented model is power order at $\mathrm{MMC}_{1}$. The results in Figure 11 (a) and (b) qualified to be used for ac network faults studies, and other indicate that the MMC based HVDC link has relative slow detailed systems studies at design stage, including design of dynamic response when compared with conventional VSC- the link and converter protection systems.

HVDC links that use two-level or neutral-point clamped

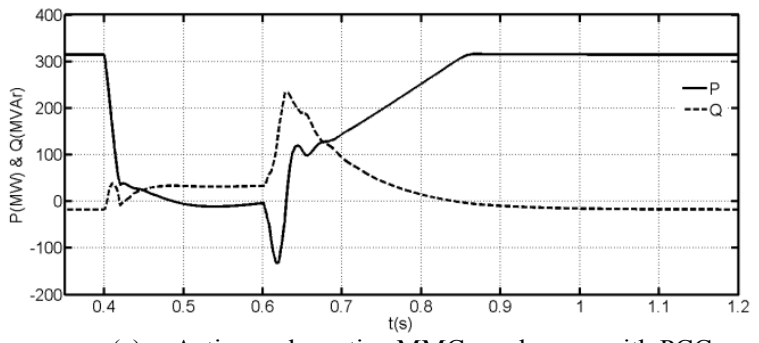

(a) Active and reactive $\mathrm{MMC}_{1}$ exchanges with $\mathrm{PCC}_{1}$

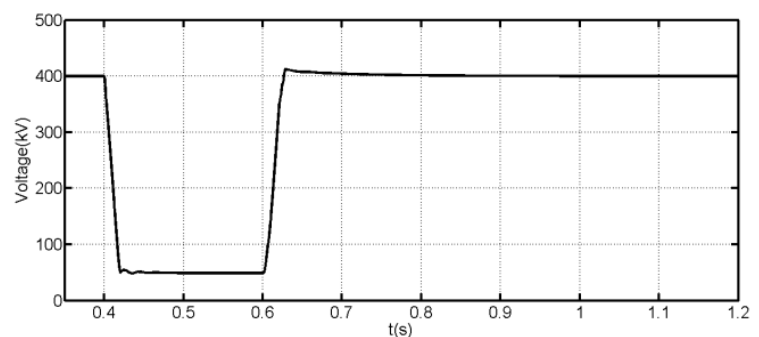

(c) Voltage magnitude at $\mathrm{PCC}_{1}$

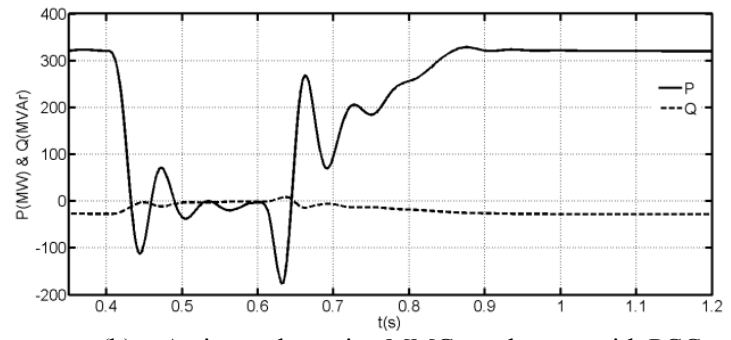

(b) Active and reactive $\mathrm{MMC}_{2}$ exchanges with $\mathrm{PCC}_{2}$

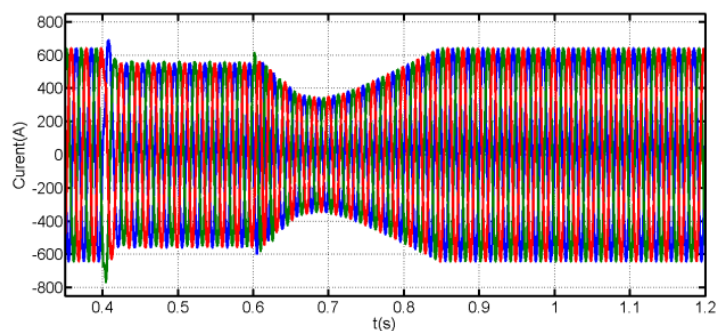

(d) Current waveforms $\mathrm{MMC}_{1}$ injects into $\mathrm{PCC}_{1}$ 
This paper is a postprint of a paper submitted to and accepted for publication in IEEE Journal of Emerging and Selected Topics in Power Electronics and is subject to Institution of Electrical and Electronic Engineering Copyright. The copy of record is available at IEEE Xplore Digital Library

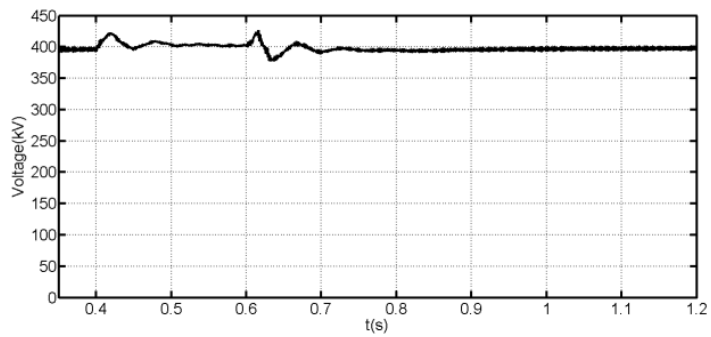

(e) $\mathrm{MMC}_{1} \mathrm{DC}$ link voltage $\left(\mathrm{V}_{\mathrm{dc} 1}\right)$

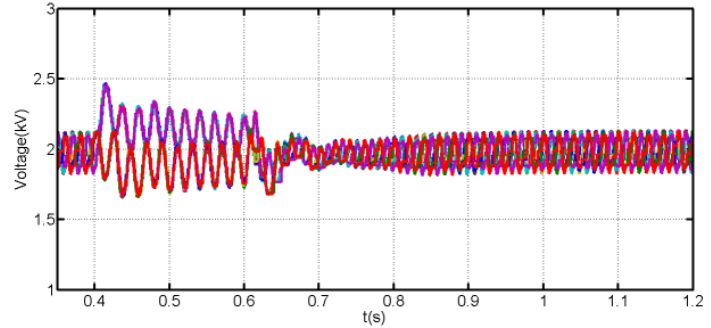

$\begin{array}{ll}(\mathrm{g}) \quad \text { Voltage across cell capacitors of phase 'A' in the } \mathrm{MMC}_{1} & (\mathrm{~h}) \text { Voltage across cell capacitors of phase 'A' in the } \mathrm{MMC}_{2}\end{array}$
Figure 11: Waveforms obtained from full-scale Simulink model in Figure 9 when it has been subjected to three-phase ac fault at PCC 1 , with 200ms fault duration

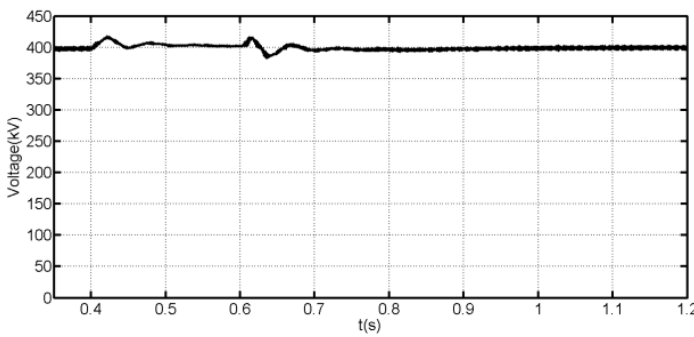

(f) $\quad \mathrm{MMC}_{2} \mathrm{DC}$ link voltage $\left(\mathrm{V}_{\mathrm{dc} 2}\right)$

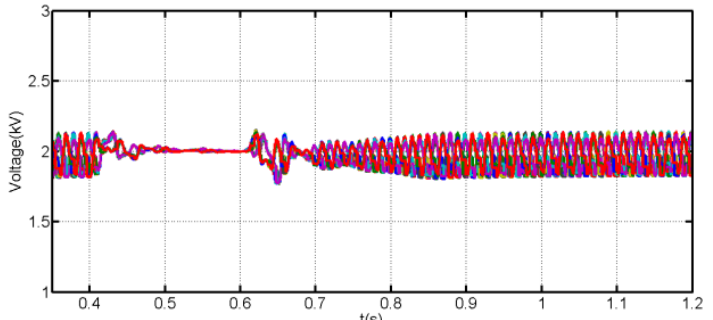

(h) Voltage across cell capacitors of phase ' $\mathrm{A}$ ' in the $\mathrm{MMC}_{2}$

middle of the HVDC link (as a sample). Figure 12 (h) and (i)

C) DC fault

To assess the suitability of the presented full-scale MMC display current waveforms in six arms of the $\mathrm{MMC}_{1}$ and based HVDC link for dc faults studies, the Simulink model of $\mathrm{MMC}_{2}$, and observe that the arm currents of both converters HVDC link in Figure 9 is subjected to a solid pole-to-pole dc tend to be negative, and this confirms that the in-feed currents short circuit fault at the middle of the dc line between $\mathrm{MMC}_{1}$ from the ac to dc sides during dc fault are flowing through and $\mathrm{MMC}_{2}$ at $\mathrm{t}=0.4 \mathrm{~s}$, with $200 \mathrm{~ms}$ fault duration. When dc fault anti-parallel diodes as expected in typical MMC link. Figure is detected, converter switches are blocked immediately. In 12 (j) and (k) show the current waveforms in the switching pre-fault condition, the link exports $315 \mathrm{MW}(0.7 \mathrm{pu})$ from ac devices $S_{a l}$ and $S_{x l}$ (top cell in the phase ' $a$ ', upper arm of the system 2 to 1 . When dc fault is detected at $\mathrm{t}=0.4 \mathrm{~s}$, power $\mathrm{MMC}_{1}$ ), and observe that there is no current in the switching command to $\mathrm{MMC}_{1}$ is reduced immediately to zero and its device $S_{x I}$ which is in series with the cell capacitor as restoration to pre-fault value is delayed until $\mathrm{t}=1 \mathrm{~s}$ to allow all anticipated in typical MMC link during dc fault when transients associated with the fault and converter de-blocking converter switches are blocked. Whilst the current in the main at $\mathrm{t}=0.6 \mathrm{~s}$ to die out. Figure 12 (a) and (b) show the HVDC link switch $S_{a l}$ is naturally commutated as in typical diode rectifier, being studied is able to recover with increased reactive power but with large overlap which is caused by present of large consumptions due to current in-feed through anti-parallel inductances in the conduction path (converter transformer diodes of $\mathrm{MMC}_{1}$ and $\mathrm{MMC}_{2}$ as expected in typical half-bridge leakage inductances plus arm reactors) when converter MMC based HVDC link. Current waveforms in Figure 12 (c) switching devices are gated off. Figure 12 (1) and (m) present and (d) show large current in-feeds at ac sides of the $\mathrm{MMC}_{1}$ the cell capacitor voltages of the $\mathrm{MMC}_{1}$ and $\mathrm{MMC}_{2}$, and and $\mathrm{MMC}_{2}$ during fault period as previously mentioned. observe that the cell capacitor voltages of the $\mathrm{MMC}_{1}$ and Figure 12 (e) and (f) display dc currents at the terminals of the $\mathrm{MMC}_{2}$ become flat when they are blocked as no currents are $\mathrm{MMC}_{1}$ and $\mathrm{MMC}_{2}$. Observe that due to the concept of following through the cell capacitors as previously shown in distributed cell capacitors of the MMC the transient Figure $12(\mathrm{k})$. Results presented in Figure 12 have shown that component of the dc fault that associated with discharge of dc the full-scale model of the MMC based HVDC link being line distributed capacitors is much smaller than the steady, simulated using converter model discussed in III-A) is able to which is mainly due to grid contribution through converter reproduce the typical behaviour of the HVDC links that anti-parallel diodes. Figure $12(\mathrm{~g})$ shows the collapse of the employ half-bridge modular multilevel converters.

$\mathrm{MMC}_{1}$ DC link voltage during pole-to-pole DC fault at the

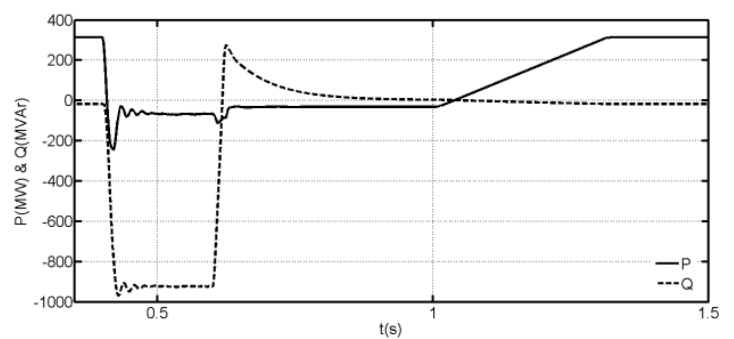

(a) Active and reactive power $\mathrm{MMC}_{1}$ exchanges with $\mathrm{PCC}_{1}$

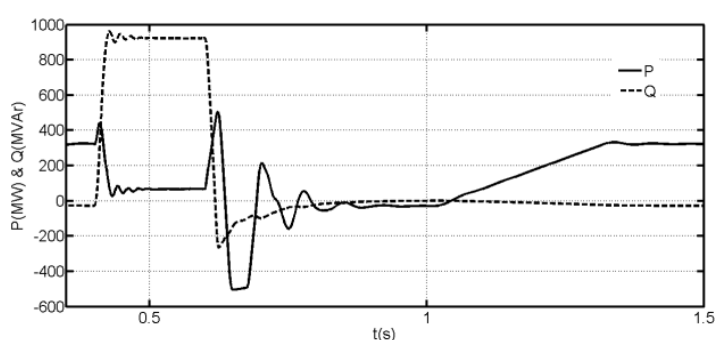

(b) Active and reactive power $\mathrm{MMC}_{2}$ exchanges with $\mathrm{PCC}_{2}$ 
This paper is a postprint of a paper submitted to and accepted for publication in IEEE Journal of Emerging and Selected Topics in Power Electronics and is subject to Institution of Electrical and Electronic Engineering Copyright. The copy of record is available at IEEE Xplore Digital Library

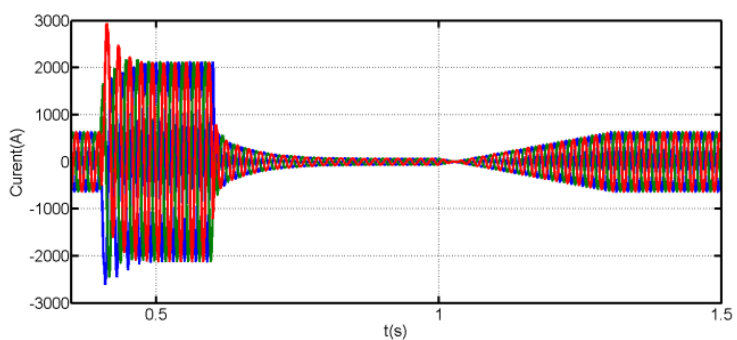

(c) Current waveforms $\mathrm{MMC}_{1}$ injects into $\mathrm{PCC}_{1}$

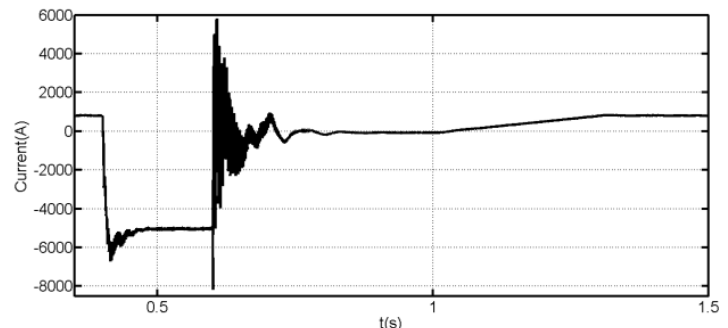

(e) $\mathrm{MMC}_{1} \mathrm{dc}$ link current

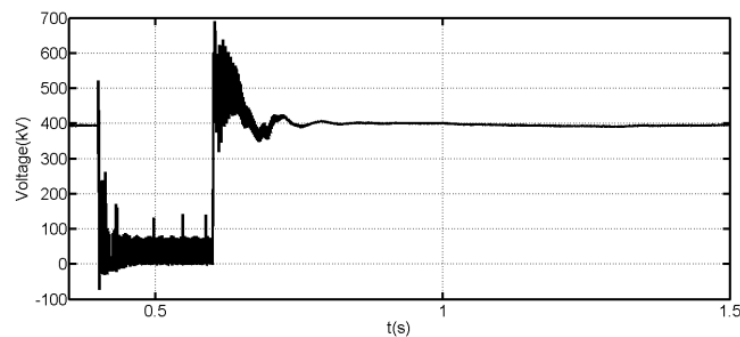

(g) Sample of the dc link voltage measured at the terminal of MMC $\left(\mathrm{V}_{\mathrm{dc} 1}\right)$

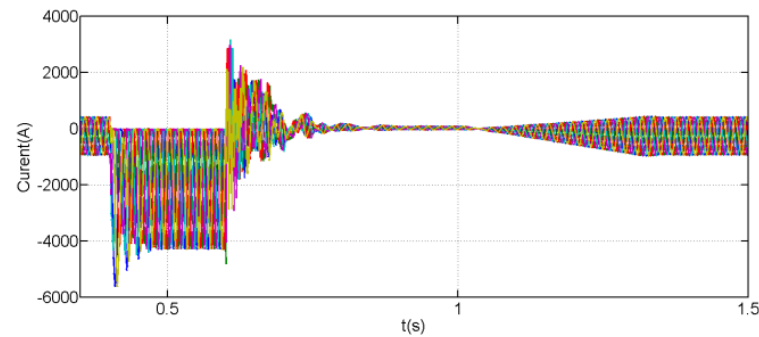

(i) Current waveforms in the six arms of the $\mathrm{MMC}_{2}$

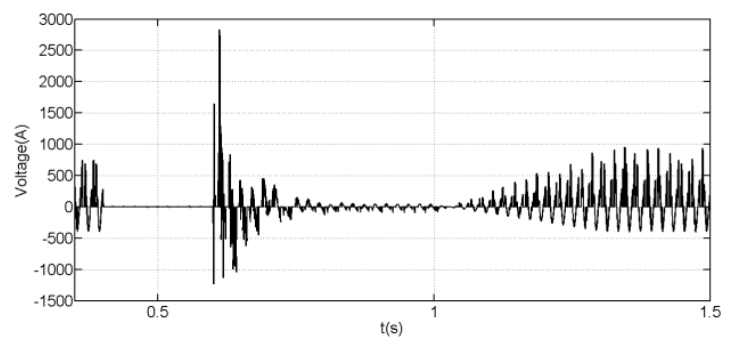

(k) Sample of the current waveform in the switching device $\mathrm{S}_{\mathrm{x} 1}\left(1^{\text {st }}\right.$ cell in upper arm of $\mathrm{MMC}_{1}$, phase 'a')

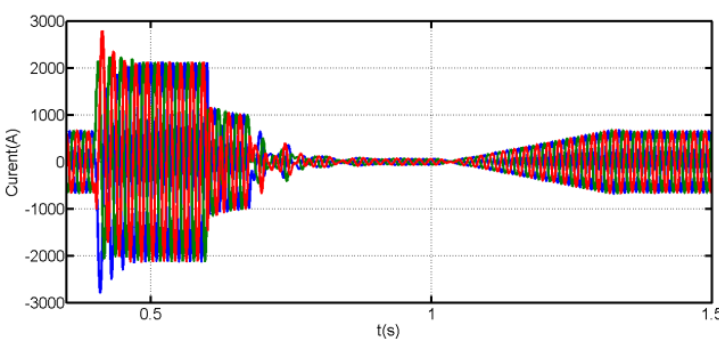

(d) Current waveforms $\mathrm{MMC}_{2}$ injects into $\mathrm{PCC}_{2}$

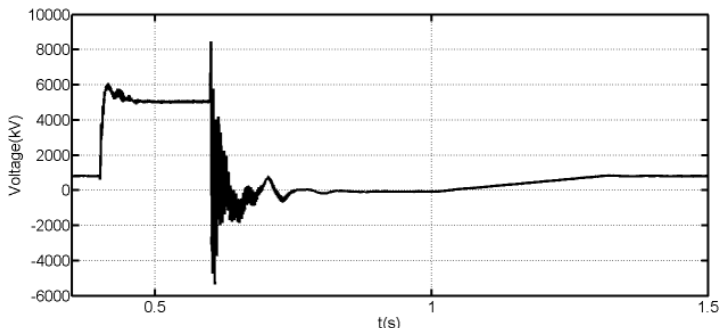

(f) $\mathrm{MMC}_{2} \mathrm{dc}$ link current

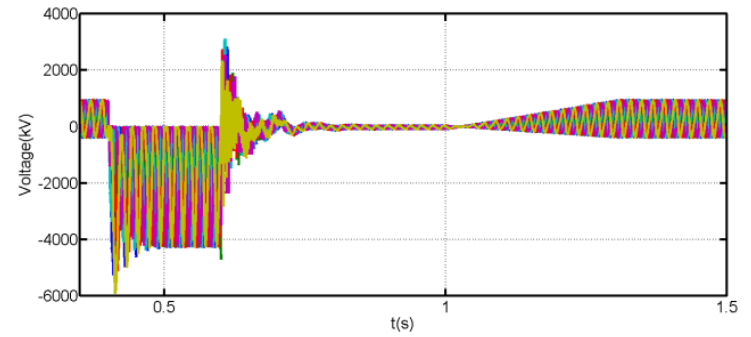

(h) Current waveforms in the six arms of the $\mathrm{MMC}_{1}$

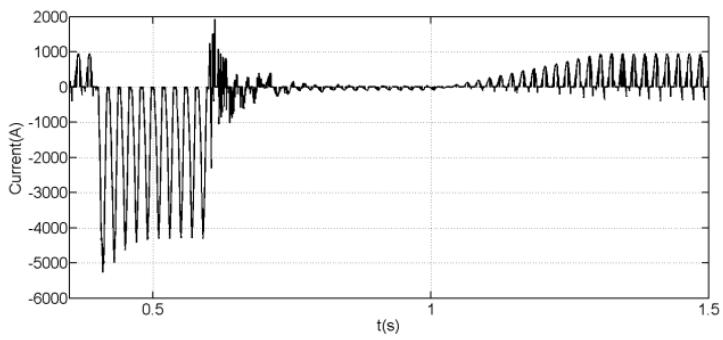

(j) Sample of the current waveform in the switching device $\mathrm{S}_{\mathrm{a} 1}\left(1^{\mathrm{s}}\right.$ cell in upper arm of $\mathrm{MMC}_{1}$, phase ' $\mathrm{a}$ ')

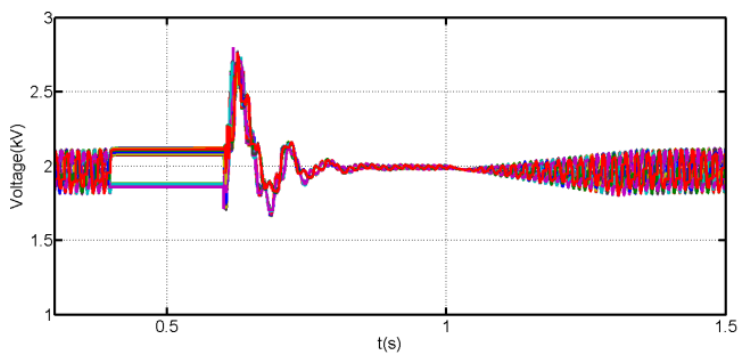

(1) Voltage across cell capacitor 402 cell capacitors of phase A of the $\mathrm{MMC}$

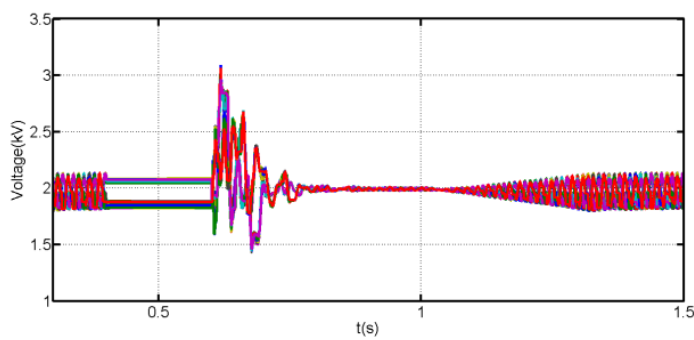

(m) Voltage across cell capacitor 402 cell capacitors of phase $\mathrm{A}$ of the $\mathrm{MMC}_{2}$

Figure 12: Waveforms obtained when a full-scale Simulink model of the MMC based HVDC link in Figure 9 is subjected to a pole-to-pole de short circuit fault 
This paper is a postprint of a paper submitted to and accepted for publication in IEEE Journal of Emerging and Selected Topics in Power Electronics and is subject to Institution of Electrical and Electronic Engineering Copyright. The copy of record is available at IEEE Xplore Digital Library

\section{CONCLUSIONS}

This paper presented improved electromagnetic transient models for the half and full MMC that can be used to simulate normal and transient responses of the full-scale HVDC links that employ modular multilevel converters, hundreds cells per arm. Additionally, it provides comprehensive qualitative and quantities discussions of the half and full-bridge MMCs that cover device and system aspects, which are of great importance for correct modelling of the MMC based HVDC links. It has been shown that the presented models can reproduce the typical behaviour of the half and full bridge MMCs as that normally obtained from the switching model. Scalabilities of both MMC models presented in this paper have demonstrated the suitability of this approach for modelling of full-scale HVDC links and multi-terminal dc grids. Unlike the previous works which are platform dependent, this paper has shown that the presented generic MMC model can be implemented in any platform.

\section{APPENDIX}

This appendix presents validations of the EMTP model discussed in section III-A against its switching counterpart during ac and dc faults, considering the test system in Figure 13. Figure 13 represents one terminal of the HVDC link which is configured to regulate active power and ac voltage at $\mathrm{PCC}_{1}$. Both models are simulated with reduced number of cells per arm (21 cells per arm), with the same control systems as depicted in Figure 8.

Figure 14 displays selected waveforms obtained when the test system in Figure 13 is subjected to a temporary three-phase fault at $\mathrm{PCC}_{1}$, at $\mathrm{t}=0.4 \mathrm{~s}$ and cleared after $200 \mathrm{~ms}$. Figure 14 (a) shows that the three-phase currents both MMC models inject into ac grid during steady state and ac fault are closely matched. Figure 14(b) presents the error between the threephase currents of the two models shown Figure 14(a), calculated as $\Delta i_{a b c}=i_{a b c}^{\text {swicth }}-i_{a b c}^{E M T P}$. Observe that the peak percentage errors during steady-state and ac fault are $2 \mathrm{~A} / 644 \mathrm{~A} \times 100 \%=0.3 \%$ and $7 \mathrm{~A} / 551 \mathrm{~A} \times 100 \%=1.27 \%$ when converter output active power is reduced to zero. Figure 14(c) and (d) show sample of the upper and lower arm currents (phase 'A') obtained from both models and their corresponding error. Observe that the results of the EMTP model agree to that of switch model to the finest details, with some limited errors during fast transient initiated by the ac fault as depicted in Figure 14 (d). Additionally, notice that as the error in Figure 14 (d) fluctuates between positive and negative, which indicates oscillations of the EMTP currents around that of the switching model. Figure 14 (d) indicates that the average error between the two models is expected to be sufficiently small. Figure 14 (e) and (f) show the common mode current $I_{a 1}+I_{a 2}$ obtained from both models and their corresponding error, and notice that both models agree to great details during steady state and ac fault, with small average error. Figure $14(\mathrm{~g})$ and $(\mathrm{h})$ display sample of the cell capacitor voltages and their zoomed version around the fault period. Observe that the EMTP model is able to reproduce similar results as that of the switching model, with sufficiently small error. Based on the results in Figure 14 it can be concluded that the presented EMTP model is able to reproduce the output of its switching counterpart, with high level of accuracy. Therefore, it qualifies for any kind of detailed studies of the ac network faults.

To further validate the dc fault performance of the presented EMTP model against its switching equivalent, the test system in Figure 13 is subjected to temporary solid pole-to-pole dc short circuit at the middle of the dc link at $\mathrm{t}=0.4$, with $200 \mathrm{~ms}$ fault duration, and results obtained are displayed in Figure 15. During dc fault period, the gating signals to converter switches are blocked, and active power command is reduced immediately to zero. Figure 15 (a) shows the snapshot of the three-phase currents converter injects into $\mathrm{PCC}_{1}$, zoomed around the fault period. Observe that both models produce almost identical results, with small relative error of less than $4 \%\left(\frac{I_{a b c}^{\text {switch }}-I_{\text {abc }}^{E M T P}}{I_{\text {arm }}^{\text {switc }}} \times 100 \%=\frac{2600 \mathrm{~A}-2700 \mathrm{~A}}{2600 \mathrm{~A}} \approx-3.85 \%\right)$ during dc fault. Such level of error is conceivable as the switch model uses relative complex model for the switching devices (IGBT and anti-parallel diode), while EMTP approach uses only twostate resistance to mimic on and off states of the switching devices. Figure 15(b) displays the snapshot of the upper and lower arm currents for phase 'A'. Observe that the presented EMTP model is able to reproduce the output of the switching model, with small relative error of less than $4 \%$ ( $\left.\frac{I_{\text {arm }}^{\text {switch }}-I_{\text {arm }}^{\text {EMTP }}}{I_{\text {arm }}^{\text {switch }}} \times 100 \%=\frac{5300 \mathrm{~A}-5500 \mathrm{~A}}{5300 \mathrm{~A}} \approx-3.77 \% \quad 200 \mathrm{~A}\right)$ during dc fault when converter switches are gated-off. This confirms the validity of the modifications introduced in the setting of the MMC two-state resistors when gating signals are inhibited as previously discussed in section III-A. Figure 15(c) displays the zoomed version of the cell capacitors (first three cell capacitor voltages from the upper and lower arms of the phase 'A'). Notice that the cell capacitor voltages obtained from the EMTP model are similar to that of the switching model, with some small error of less than $1 \%$ during dc fault period.

Simulation waveforms presented in Figure 14 and Figure 15 have shown that the presented EMTP model is sufficiently accurate to be used for wide range of the detailed studies of full-scale HVDC links and multi-terminal HVDC networks, including ac and dc faults. 
This paper is a postprint of a paper submitted to and accepted for publication in IEEE Journal of Emerging and Selected Topics in Power Electronics and is subject to Institution of Electrical and Electronic Engineering Copyright. The copy of record is available at IEEE Xplore Digital Library

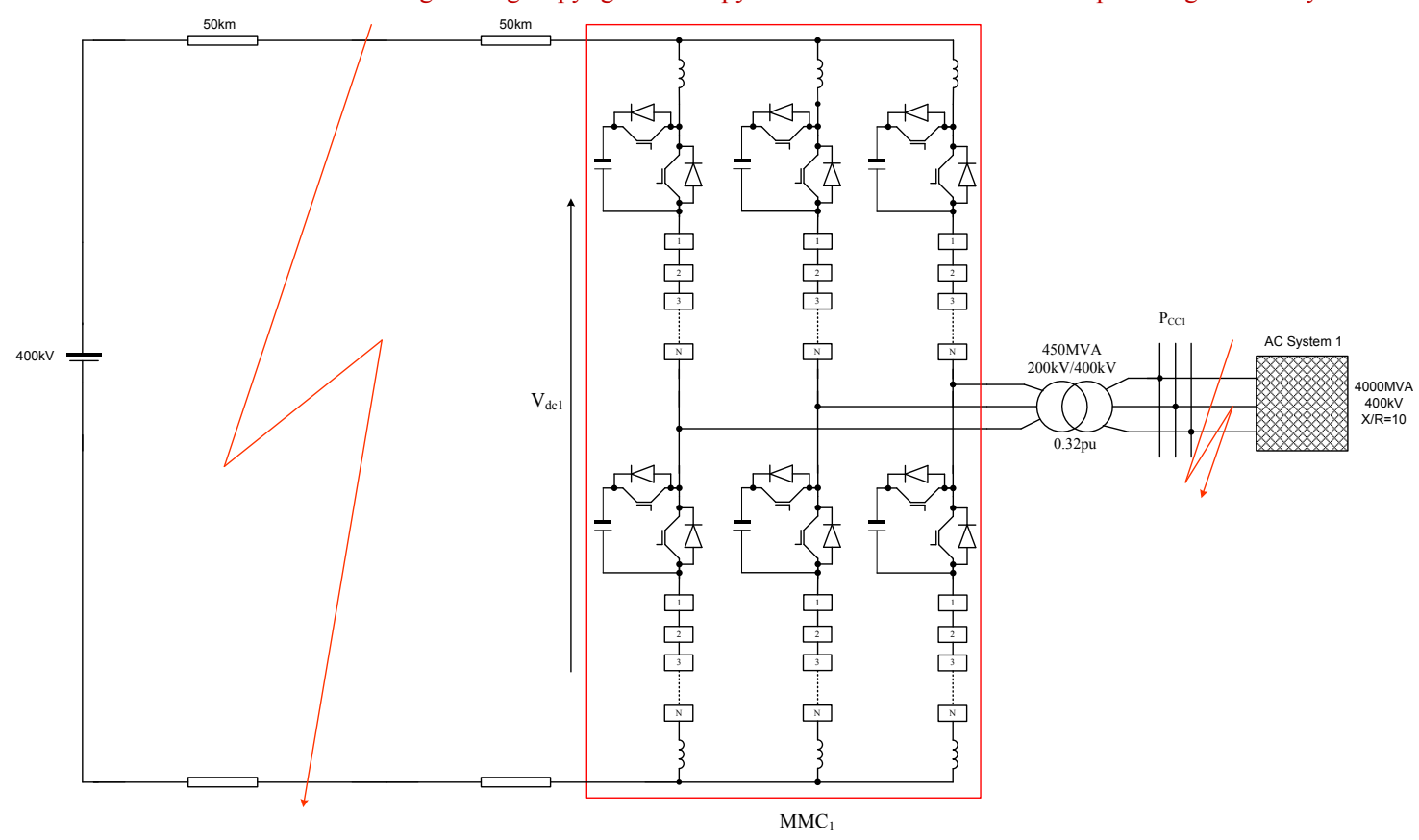

Figure 13: One terminal of the MMC HVDC link used to validate the present EMTP against its switching counterpart, with number of cells per arm is reduced to 21 and cell capacitance $1.4 \mathrm{mF}$

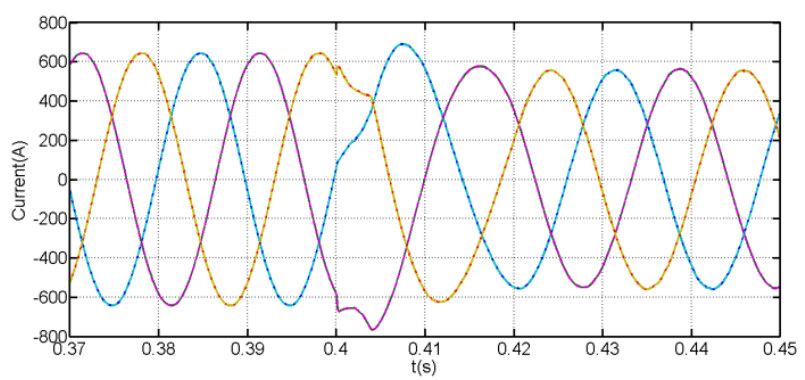

(a) Snapshot of the three-phase currents converter injects into grid zero around the time where the fault is initiated (switch model superimposed on that obtained from EMT model)

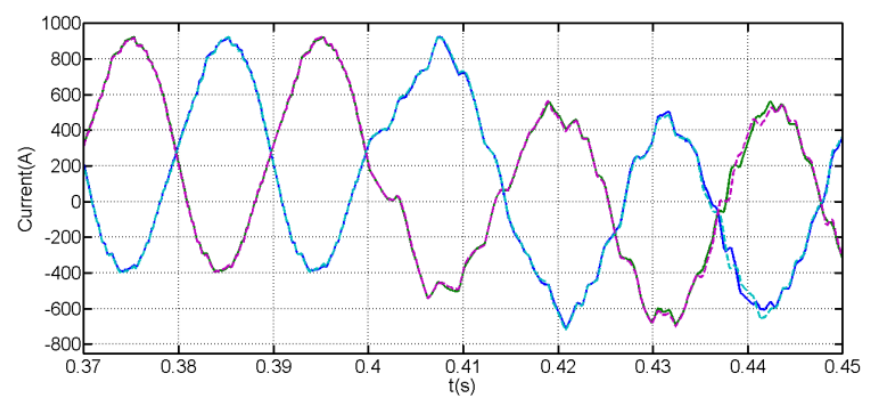

(c) Snapshot of the upper and lower arm currents zoomed around the instant where the ac fault is initiated (phase 'A', switch model superimposed on that obtained from EMT model)

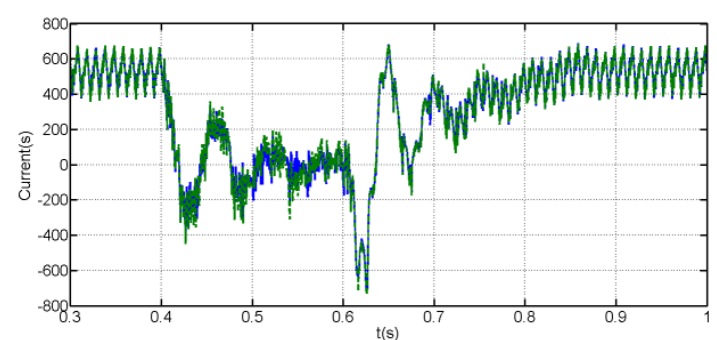

(e) Common mode currents $I_{a l}+I_{a 2}$ (phase 'A', switch model superimposed on that obtained from EMT model)

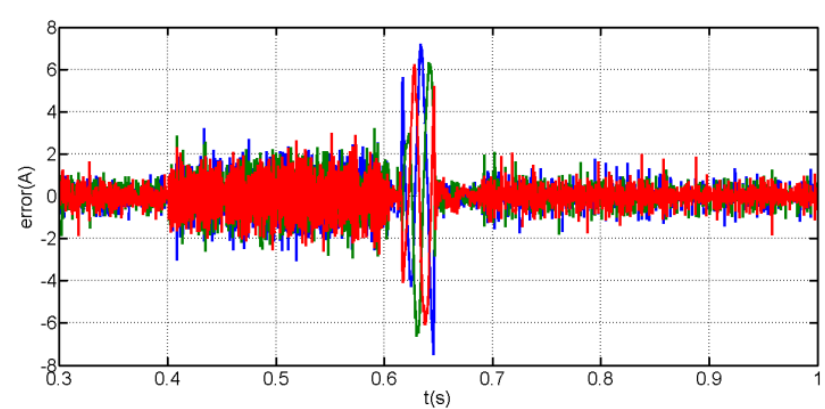

(b) Errors between the two models in the currents converter station injects into ac grid

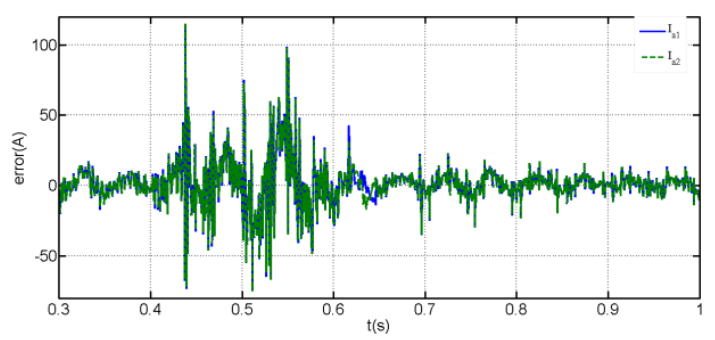

(d) Errors in the arm currents between the two models

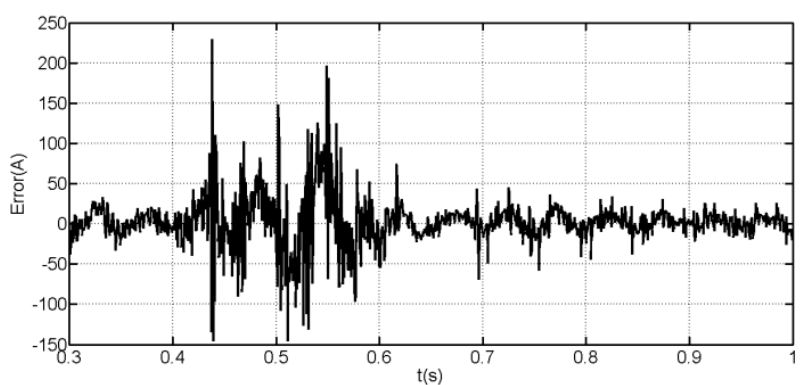

(f) Error in common mode current 
This paper is a postprint of a paper submitted to and accepted for publication in IEEE Journal of Emerging and Selected Topics in Power Electronics and is subject to Institution of Electrical and Electronic Engineering Copyright. The copy of record is available at IEEE Xplore Digital Library

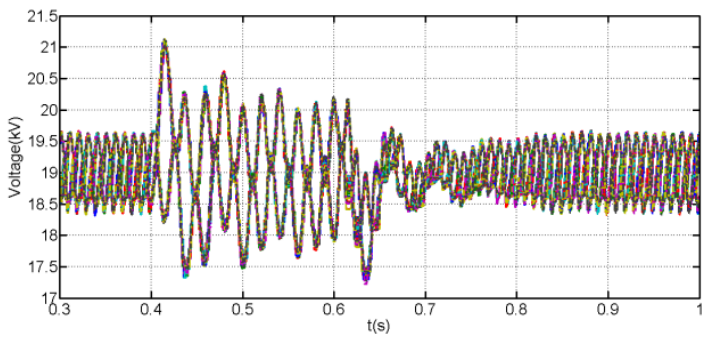

(g) Sample of cell capacitor voltages (phase 'A' upper and lower arms, switch model superimposed on that obtained from EMT model)

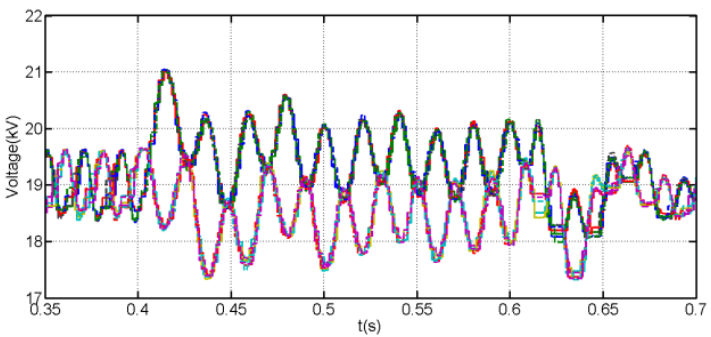

(h) Detailed view of the cell capacitor voltages zoomed around the instant where the fault is initiated (three first cells from the upper and lower arms of phase 'A', switch model superimposed on that obtained from EMT model)

Figure 14: Waveforms aim to validate the presented EMTP model versus its switching equivalent during three-phase ac fault at PCC $(21$ cells per arm, 450MVA converter with 400kV dc link voltage)

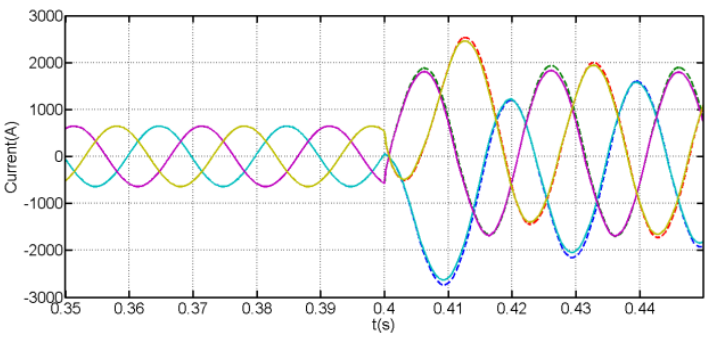

(a) Snapshot of the three-phase currents measured at the converter transformer high-voltage side $(400 \mathrm{kV}$, grid side), zoomed around instant when de fault is initiated

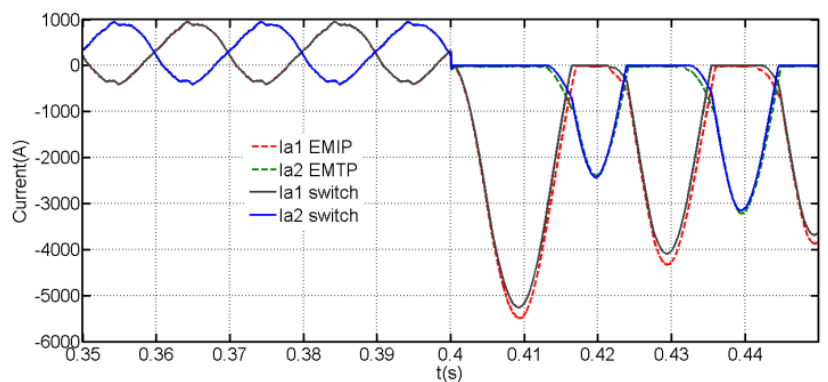

(b) Phase 'A' upper and lower arm currents (switch model superimposed on that obtained from EMT model), zoomed around instant when de fault is initiated

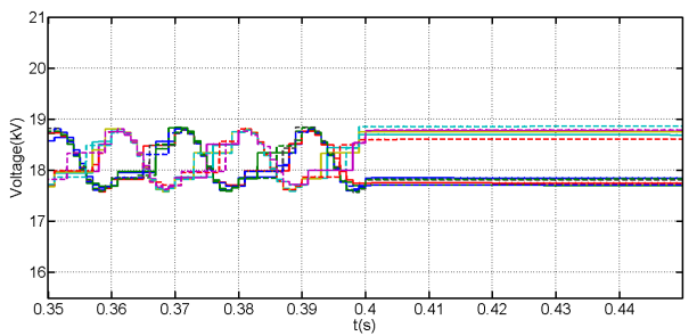

(c) Detailed view of the cell capacitor voltages zoomed around the instant where the fault is initiated (three first cells from the upper and lower arms of phase 'A', switch model superimposed on that obtained from EMT model)

Figure 15: Waveforms aim to validate the presented EMTP model versus its switching equivalent during solid pole-to-pole dc short circuit fault at $\mathrm{F}_{2}(21$ cells per arm, 450MVA converter with $400 \mathrm{kV}$ dc link voltage, dc cable )

IX. REFERENCES
M. P. Bahrman and B. K. Johnson, "The ABCs of HVDC transmission technologies," Power and Energy Magazine, IEEE, vol. 5, pp. 32-44, 2007

S. Karugaba and O. Ojo, "A Carrier-Based PWM Modulation Technique for Balanced and Unbalanced Reference Voltages in Multiphase Voltage-Source Inverters," Industry Applications, IEEE Transactions on, vol. 48, pp. 2102-2109, 2012.

L. Chi-Seng, C. Wai-Hei, W. Man-Chung, and H. Ying-Duo, "Adaptive DC-Link Voltage-Controlled Hybrid Active Power Filters for Reactive Power Compensation," Power Electronics, IEEE Transactions on, vol. 27, pp. 1758-1772, 2012.

M. A. Sayed and T. Takeshita, "All Nodes Voltage Regulation and Line Loss Minimization in Loop Distribution Systems Using UPFC," Power Electronics, IEEE Transactions on, vol. 26, pp. 1694-1703, 2011.

A. Lopez, R. Diez, G. Perilla, and D. Patino, "Analysis and Comparison of Three Topologies of the Ladder Multilevel DC/DC Converter," Power Electronics, IEEE Transactions on, vol. 27, pp. 3119-3127, 2012.

S. Wensheng, F. Xiaoyun, and K. M. Smedley, "A Carrier-Based PWM Strategy With the Offset Voltage Injection for Single-Phase Three-Level Neutral-Point-Clamped Converters," Power Electronics, IEEE Transactions on, vol. 28, pp. 1083-1095, 2013.
J. Pou, J. Zaragoza, S. Ceballos, M. Saeedifard, and D. Boroyevich, "A Carrier-Based PWM Strategy With Zero-Sequence Voltage Injection for a Three-Level Neutral-Point-Clamped Converter," Power Electronics, IEEE Transactions on, vol. 27, pp 642-651, 2012.

M. Hagiwara, R. Maeda, and H. Akagi, "Control and Analysis of the Modular Multilevel Cascade Converter Based on Double-Star Chopper-Cells (MMCC-DSCC)," Power Electronics, IEEE Transactions on, vol. PP, pp. 1-1, 2010.

M. Hagiwara, R. Maeda, and H. Akagi, "Control and Analysis of the Modular Multilevel Cascade Converter Based on Double-Star Chopper-Cells (MMCC-DSCC)," Power Electronics, IEEE Transactions on, vol. 26, pp. 1649-1658, 2011.

H. Akagi and R. Kitada, "Control and Design of a Modular Multilevel Cascade BTB System Using Bidirectional Isolated DC/DC Converters," Power Electronics, IEEE Transactions on, vol. 26, pp. 2457-2464, 2011.

[11] K. R. Sekhar and S. Srinivas, "Discontinuous Decoupled PWMs for Reduced Current Ripple in a Dual Two-Level Inverter Fed Open-End Winding Induction Motor Drive," Power Electronics, IEEE Transactions on, vol. 28, pp. 2493-2502, 2013.

Z. Zhengming, Z. Yulin, G. Hongwei, Y. Liqiang, and L. Ting, "Hybrid Selective Harmonic Elimination PWM for CommonMode Voltage Reduction in Three-Level Neutral-Point-Clamped Inverters for Variable Speed Induction Drives," Power Electronics, IEEE Transactions on, vol. 27, pp. 1152-1158, 2012. 
This paper is a postprint of a paper submitted to and accepted for publication in IEEE Journal of Emerging and Selected Topics in Power Electronics and is subject to Institution of Electrical and Electronic Engineering Copyright. The copy of record is available at IEEE Xplore Digital Library

[13] F. Gunnar, C.-G. Carlsson, and R.S.Moni, "Global Trends in Bulk [34] Power Transmission," ABB Utilities AB., S-77180, Ludvika, Sweden.

[14] O. Heyman. (December 2012) HVDC Light: It is time to connect. [35] Available: www.abb.com/hvdc

[15] M. Davies, M. Dommaschk, J. L. J. Dorn, D. Retzmann, and D. Soerangr. HVDC PLUS - Basics and Principle of Operation [Online].

[16] K. Friedrich, "Modern HVDC PLUS application of VSC in [36] Modular Multilevel Converter topology," in Industrial Electronics (ISIE), 2010 IEEE International Symposium on, 2010, pp. $3807-$ 3810.

[17] M. Spichartz, V. Staudt, and A. Steimel, "Modular Multilevel Converter for propulsion system of electric ships," in Electric Ship Technologies Symposium (ESTS), 2013 IEEE, 2013, pp. 237-242.

[18] H. J. Knaak, "Modular multilevel converters and HVDC/FACTS: A success story," in Power Electronics and Applications (EPE 2011), Proceedings of the 2011-14th European Conference on, 2011, pp. 1-6.

[19] E. Dirk, A. Krummholz, D. Retzmann, and K. Uecker, "Prospects of HVDC\&FACTS for Bulk Power Transmission and System Security."

[20] F. Deng and Z. Chen, "A Control Method for Voltage Balancing in Modular Multilevel Converters," Power Electronics, IEEE Transactions on, vol. 29, pp. 66-76, 2014

[21] G. Congzhe, J. Xinjian, L. Yongdong, C. Zhe, and L. Jingyun, "A DC-Link Voltage Self-Balance Method for a Diode-Clamped Modular Multilevel Converter With Minimum Number of Voltage Sensors," Power Electronics, IEEE Transactions on, vol. 28, pp. 2125-2139, 2013.

[22] M. K. Alam and F. H. Khan, "EFFICIENCY CHARACTERIZATION AND IMPEDANCE MODELING OF A MULTILEVEL SWITCHED CAPACITOR CONVERTER USING PULSE DROPPING SWITCHING SCHEME" Power Electronics, IEEE Transactions on, vol. PP, pp. 1-1, 2013

[23] L. Zixin, W. Ping, Z. Haibin, C. Zunfang, and L. Yaohua, "An Improved Pulse Width Modulation Method for Chopper-CellBased Modular Multilevel Converters," Power Electronics, IEEE Transactions on, vol. 27, pp. 3472-3481, 2012

[24] M. Rashed, C. Klumpner, and G. Asher, "Repetitive and Resonant Control for a Single-Phase Grid-Connected Hybrid Cascaded Multilevel Converter," Power Electronics, IEEE Transactions on, vol. 28, pp. 2224-2234, 2013.

[25] S. Zeliang, H. Xiaoqiong, W. Zhiyong, Q. Daqiang, and J. Yongzi, "Voltage Balancing Approaches for Diode-Clamped Multilevel Converters Using Auxiliary Capacitor-Based Circuits," Power Electronics, IEEE Transactions on, vol. 28, pp. 2111-2124, 2013.

[26] J. Chivite-Zabalza, P. Izurza-Moreno, D. Madariaga, G. Calvo, Rodri, $\mathrm{x}$, et al., "Voltage Balancing control in 3-Level NeutralPoint Clamped Inverters Using Triangular Carrier PWM Modulation for FACTS Applications," Power Electronics, IEEE Transactions on, vol. 28, pp. 4473-4484, 2013.

[27] G. P. Adam, S. J. Finney, and B. W. Williams, "Hybrid converter with ac side cascaded $\mathrm{H}$-bridge cells against $\mathrm{H}$-bridge alternative arm modular multilevel converter: steady-state and dynamic [47] performance," Generation, Transmission \& Distribution, IET, vol. 7, 2013.

[28] J. Peralta, H. Saad, S. Dennetiere, J. Mahseredjian, and S. Nguefeu, "Detailed and Averaged Models for a 401-Level [48] MMC\&\#x2013;HVDC System," Power Delivery, IEEE Transactions on, vol. 27, pp. 1501-1508, 2012.

[29] H. Saad, J. Peralta, S. Dennetiere, J. Mahseredjian, J. Jatskevich, J. A. Martinez, et al., "Dynamic Averaged and Simplified Models for MMC-Based HVDC Transmission Systems," Power Delivery, IEEE Transactions on, vol. 28, pp. 1723-1730, 2013.

[30] U. N. Gnanarathna, A. M. Gole, and R. P. Jayasinghe, "Efficient Modeling of Modular Multilevel HVDC Converters (MMC) on Electromagnetic Transient Simulation Programs," Power Delivery, IEEE Transactions on, vol. 26, pp. 316-324, 2011.

[31] X. Jianzhong, Z. Chengyong, L. Wenjing, and G. Chunyi, "Accelerated Model of Modular Multilevel Converters in PSCAD/EMTDC," Power Delivery, IEEE Transactions on, vol. [51] 28 , pp. 129-136, 2013

[32] G. Kron, "A Set of Principles to Interconnect the Solutions of Physical Systems," Journal of Applied Physics, vol. 24, pp. $965-$ 980, 1953.

[33] A. Wexler, J. A. Dobrowalski, and A. E. Hammad, "Solution of Large, Sparse Systms in Design and Analysis," in Microwave Symposium, 1975 IEEE-MTT-S International, 1975, pp. 202-203.
G. Kron, "A Method to Solve Very Large Physical Systems in Easy Stages," Circuit Theory, Transactions of the IRE Professional Group on, vol. PGCT-2, pp. 71-90, 1953.

G. P. Adam, S. J. Finney, K. H. Ahmed, and B. W. Williams, "Modular multilevel converter modeling for power system studies," in Power Engineering, Energy and Electrical Drives (POWERENG), 2013 Fourth International Conference on, 2013, pp. 1538-1542.

T. Maguire;, B. Warkentin;, Y. Chen;, and J.-P. Hasler, "Efficient Techniques for Real Time Simulation of MMC systems," presented at the International Conference on Power Systems Transients (IPST2013), Vancouver, Canada, 2013.

O. Venjakob;, S. Kubera;, R. Hibberts-Caswell;, P. A. Forsyth; and T. L. Maguire, "Setup and Performance of the Real-Time Simulator used for Hardware Scheme for Offshore Applications," presented at the International Conference on Power Systems Transients (IPST2013), Vancouver, Canada, 2013.

J. Rodriguez, S. Bernet, W. Bin, J. O. Pontt, and S. Kouro, "Multilevel Voltage-Source-Converter Topologies for Industrial Medium-Voltage Drives," Industrial Electronics, IEEE Transactions on, vol. 54, pp. 2930-2945, 2007.

[39] S. Shuai, P. W. Wheeler, J. C. Clare, and A. J. Watson, "Fault Detection for Modular Multilevel Converters Based on Sliding Mode Observer," Power Electronics, IEEE Transactions on, vol. 28, pp. 4867-4872, 2013

S. Jianjiang, G. Wei, Y. Hao, Z. Tiefu, and A. Q. Huang, "Research on Voltage and Power Balance Control for Cascaded Modular Solid-State Transformer," Power Electronics, IEEE Transactions on, vol. 26, pp. 1154-1166, 2011.

[41] Y. Zhang, G. P. Adam, T. C. Lim, S. J. Finney, and B. W. Williams, "Analysis of modular multilevel converter capacitor voltage balancing based on phase voltage redundant states," Power Electronics, IET, vol. 5, pp. 726-738, 2012

G. P. Adam, K. H. Ahmed, S. J. Finney, and B. W. Williams, "Modular multilevel converter for medium-voltage applications," in Electric Machines \& Drives Conference (IEMDC), 2011 IEEE International, 2011, pp. 1013-1018.

Y. Zhang1, G. P. Adam2, T.C.Lim, S. J. Finney, and a. B. W. Williams, "Voltage Source Converter in High Voltage Applications: Multilevel versus Two-level Converters," in IET, the 9th International Conference on AC and DC Power Transmission, London, UK, 2010.

[44] S. Xu, A. Huang, N. Xijun, and R. Burgos, "AC circulating currents suppression in modular multilevel converter," in IECON 2012 - 38th Annual Conference on IEEE Industrial Electronics Society, 2012, pp. 191-196.

K. Ilves, S. Norrga, L. Harnefors, and H. P. Nee, "Analysis of arm current harmonics in modular multilevel converters with maincircuit filters," in Systems, Signals and Devices (SSD), 2012 9th International Multi-Conference on, 2012, pp. 1-6.

L. Yalong and F. Wang, "Arm inductance selection principle for modular multilevel converters with circulating current suppressing control," in Applied Power Electronics Conference and Exposition (APEC), 2013 Twenty-Eighth Annual IEEE, 2013, pp. 1321-1325.

M. Ji-Woo, K. Chun-Sung, P. Jung-Woo, K. Dea-Wook, and K. Jang-Mok, "Circulating Current Control in MMC Under the Unbalanced Voltage," Power Delivery, IEEE Transactions on, vol. 28, pp. 1952-1959, 2013.

K. Ilves, A. Antonopoulos, L. Harnefors, S. Norrga, and H. P. Nee, "Circulating current control in modular multilevel converters with fundamental switching frequency," in Power Electronics and Motion Control Conference (IPEMC), 2012 7th International, 2012, pp. 249-256.

$\mathrm{S} . \mathrm{Xu}$ and $\mathrm{A}$. Huang, "Circulating current control of double-star chopper-cell modular multilevel converter for HVDC system," in IECON 2012 - 38th Annual Conference on IEEE Industrial Electronics Society, 2012, pp. 1234-1239.

Y. Xiaofeng, L. Jianghong, W. Xiaopeng, F. Wenbao, and T. Q. Zheng, "Circulating Current Model of Modular Multilevel Converter," in Power and Energy Engineering Conference (APPEEC), 2011 Asia-Pacific, 2011, pp. 1-6.

T. Qingrui, X. Zheng, and Z. Jing, "Circulating current suppressing controller in modular multilevel converter," in IECON 2010 - 36th Annual Conference on IEEE Industrial Electronics Society, 2010, pp. 3198-3202.

M. Zhang, L. Huang, W. Yao, and Z. Lu, "Circulating Harmonic Current Elimination of a CPS-PWM Based Modular Multilevel Converter with Plug-In Repetitive Controller," Power Electronics, IEEE Transactions on, vol. PP, pp. 1-1, 2013. 
This paper is a postprint of a paper submitted to and accepted for publication in IEEE Journal of Emerging and Selected Topics in Power Electronics and is subject to Institution of Electrical and Electronic Engineering Copyright. The copy of record is available at IEEE Xplore Digital Library

[53] B. Jacobson;, P. Karlsson;, G.Asplund; L.Harnnart; and a. T. Jonsson, "VSC-HVDC Transmission with Cascaded Two-level Converters," presented at the CIGRE 2010, 2010.

[54] D. Schmitt, Y. Wang, T. Weyh, and R. Marquardt, "DC-side fault current management in extended multiterminal-HVDCgrids," in Systems, Signals and Devices (SSD), 2012 9th International Multi-Conference on, 2012, pp. 1-5.

[55] R. Marquardt, "Modular Multilevel Converter topologies with DC-Short circuit current limitation," in Power Electronics and ECCE Asia (ICPE \& ECCE), 2011 IEEE 8th International Conference on, 2011, pp. 1425-1431.

[56] R. Marquardt, "Modular Multilevel Converter: An universal concept for HVDC-Networks and extended DC-Bus-applications," in Power Electronics Conference (IPEC), 2010 International, 2010, pp. 502-507.

[57] S. Allebrod, R. Hamerski, and R. Marquardt, "New transformerless, scalable Modular Multilevel Converters for HVDC-transmission," in Power Electronics Specialists Conference, 2008. PESC 2008. IEEE, 2008, pp. 174-179.

[58] S. Rohner, S. Bernet, M. Hiller, and R. Sommer, "Analysis and Simulation of a $6 \mathrm{kV}, 6$ MVA Modular Multilevel Converter," in Industrial Electronics, 2009. IECON '09. 35th Annual Conference of IEEE, 2009, pp. 225-230.

[59] G. P. Adam;, K. H. Ahmed; S. J. Finney;, and B. W. Williams, "H-BRIDGE MODULAR MULTILEVEL CONVERTER (M2C) FOR HIGH-VOLTAGE APPLICATIONS," presented at the 21st International Conference on Electricity Distribution (Cired), Frankfurt, 2011.

[60] G. P. Adam, G. O. Anaya-Lara, and G. Burt, "Statcom based on modular multilevel converter: Dynamic performance and transient response during ac network disturbances," in Power Electronics, Machines and Drives (PEMD 2012), 6th IET International Conference on, 2012, pp. 1-5.

[61] G. P. Adam, O. Anaya-Lara, G. M. Burt, D. Telford, B. W. Williams, and J. R. McDonald, "Modular multilevel inverter: Pulse width modulation and capacitor balancing technique," Power Electronics, IET, vol. 3, pp. 702-715, 2010.

[62] N. N. V. Surendra Babu and B. G. Fernandes, "Cascaded two-level inverter-based multilevel static VAr compensator using 12-sided polygonal voltage space vector modulation," Power Electronics, IET, vol. 5, pp. 1500-1509, 2012.

[63] R. L. Sellick, x030A, and M. kerberg, "Comparison of HVDC Light (VSC) and HVDC Classic (LCC) site aspects, for a 500MW $400 \mathrm{kV}$ HVDC transmission scheme," in $A C$ and DC Power Transmission (ACDC 2012), 10th IET International Conference on, 2012, pp. 1-6.

[64] D. Retzmann. (2008, Benefits of Power Electronics Understanding HVDC and FACTS.

\section{BIOGRAPHIES}

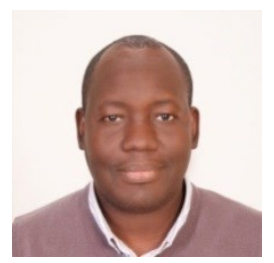

G.P. Adam received a first class BSc and MSc from Sudan University for Science and Technology, Sudan in 1998 and 2002 respectively; and. a PhD in Power Electronics from University of Strathclyde in 2007. He has been working as a research fellow with Institute of Energy and Environment, University of Strathclyde in Glasgow, UK, since 2008. His research interests are fault tolerant voltage source converters for HVDC systems; control of HVDC transmission systems and multi-terminal HVDC networks; voltage source converter based FACTS devices; and grid integration issues of renewable energies. Dr Adam has authored and co-authored several technical reports, and journal and conference papers in the area of multilevel converters and HVDC systems, and grid integration of renewable power. Also, he is actively contributing to reviewing process for several IEEE and IET Transactions and Journals, and conferences.

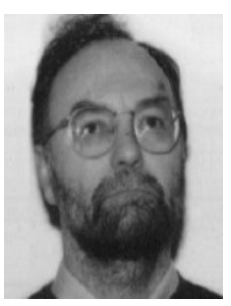

B.W. Williams received the M.Eng.Sc. degree from the University of Adelaide, Australia, in 1978, and the Ph.D. degree from Cambridge University, Cambridge, U.K., in 1980. After seven years as a Lecturer at Imperial College, University of London, U.K., he was appointed to a Chair of Electrical Engineering at Heriot-Watt University, Edinburgh, U.K, in 1986. He is currently a Professor at Strathclyde University, UK. His teaching covers power electronics (in which he has a free internet text) and drive systems. His research activities include power semiconductor modelling and protection, converter topologies, soft switching techniques, and application of ASICs and microprocessors 